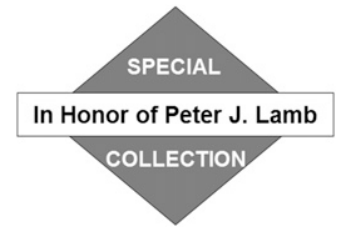

\title{
¿Why Do Global Climate Models Struggle to Represent Low-Level Clouds in the West African Summer Monsoon? 0
}

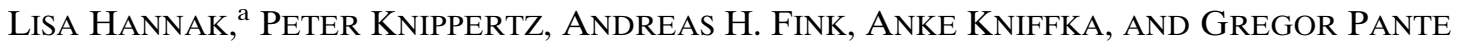 \\ Institute of Meteorology and Climate Research, Karlsruhe Institute of Technology, Karlsruhe, Germany
}

(Manuscript received 14 June 2016, in final form 14 November 2016)

\begin{abstract}
Climate models struggle to realistically represent the West African monsoon (WAM), which hinders reliable future projections and the development of adequate adaption measures. Low-level clouds over southern West Africa $\left(5^{\circ}-10^{\circ} \mathrm{N}, 8^{\circ} \mathrm{W}-8^{\circ} \mathrm{E}\right)$ during July-September are an integral part of the WAM through their effect on the surface energy balance and precipitation, but their representation in climate models has received little attention. Here 30 (20) years of output from 18 (8) models participating in phase 5 of the Coupled Model Intercomparison Project (Year of Tropical Convection) are used to identify cloud biases and their causes. Compared to ERA-Interim reanalyses, many models show large biases in low-level cloudiness of both signs and a tendency to too high elevation and too weak diurnal cycles. At the same time, these models tend to have too strong low-level jets, the impact of which is unclear because of concomitant effects on temperature and moisture advection as well as turbulent mixing. Part of the differences between the models and ERA-Interim appear to be related to the different subgrid cloud schemes used. While nighttime tendencies in temperature and humidity are broadly realistic in most models, daytime tendencies show large problems with the vertical transport of heat and moisture. Many models simulate too low near-surface relative humidities, leading to insufficient low cloud cover and abundant solar radiation, and thus a too large diurnal cycle in temperature and relative humidity. In the future, targeted model sensitivity experiments will be needed to test possible feedback mechanisms between low clouds, radiation, boundary layer dynamics, precipitation, and the WAM circulation.
\end{abstract}

\section{Introduction}

The weather and climate in West Africa are characterized by the West African monsoon (WAM) system. During boreal summer differential heating of land and ocean together with upwelling of colder waters create a marked horizontal pressure gradient between the Saharan heat low (SHL) and the tropical Atlantic Ocean, which drives the southwesterly monsoonal flow

Denotes content that is immediately available upon publication as open access.

Supplemental information related to this paper is available at the Journals Online website: http://dx.doi.org/10.1175/ JCLI-D-16-0451.s1.

${ }^{\mathrm{a}}$ Current affiliation: German Weather Service, Offenbach, Germany.

Corresponding author e-mail: Prof. Dr. Peter Knippertz, peter. knippertz@kit.edu
(Eltahir and Gong 1996; Hall and Peyrillé 2006). The WAM circulation controls winds, temperature, clouds, and most importantly precipitation over a large area. Monsoonal rainfall affects the livelihoods of hundreds of millions of people through its impacts on agriculture, health, water resources, and power generation. The large interannual to decadal variations of the WAM can have catastrophic consequences for the local population (Benson and Clay 1998; Nicholson 2001). Therefore, a reliable weather, seasonal, and decadal climate prediction is crucial for many planning activities across the region.

Despite these important socioeconomic implications, substantial model errors with respect to key features of the WAM still exist (Agustí-Panareda et al. 2010; Meynadier et al. 2010; Xue et al. 2010), leading to a lack of skill in seasonal and decadal prediction (Vellinga et al. 2013; Paxian et al. 2016) and to large intermodel spread and low confidence in climate projections, especially for precipitation (Christensen et al. 2013; Roehrig et al. 2013). The remaining known model errors include 


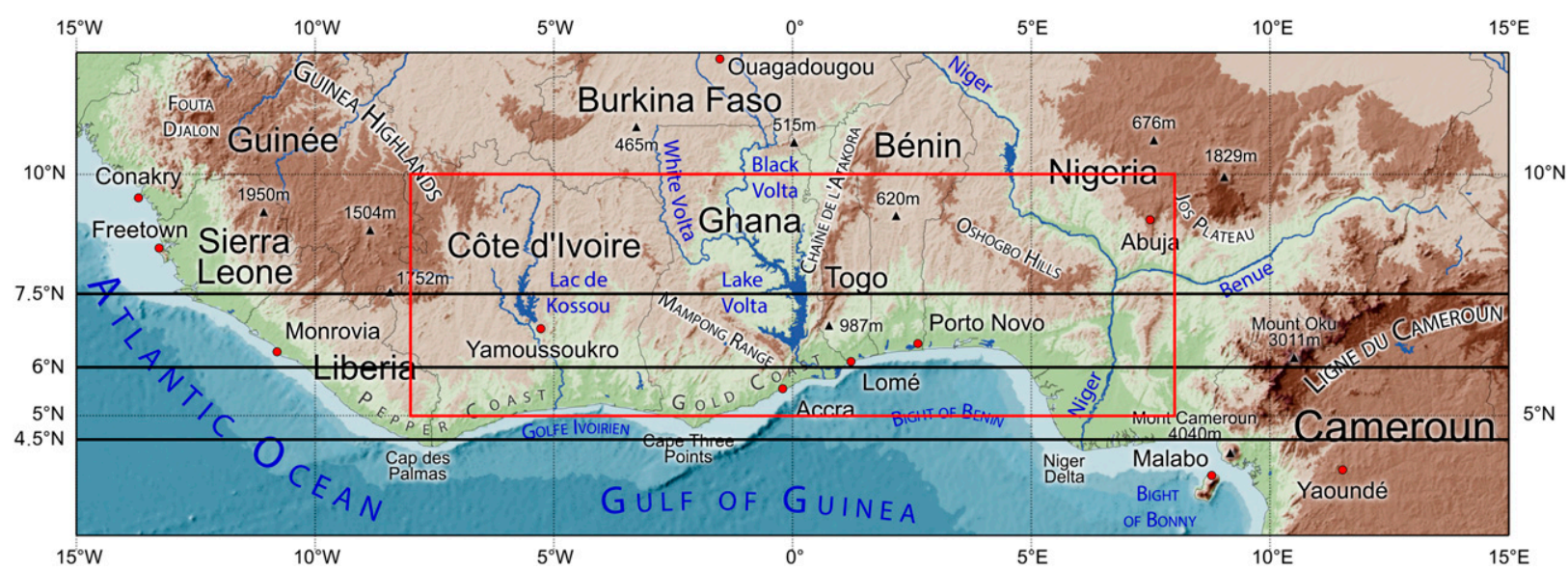

FIG. 1. Geographical overview of the study area. Given are country names, major cities, and various topographic features. The red box marks the area used for spatial averaging. Zonal black lines mark the latitudes used for the computation of advection. See section $2 \mathrm{c}$ for more details.

those associated with the radiative imbalance in the SHL (Milton et al. 2008), air-sea interactions over the tropical eastern Atlantic Ocean (Brandt et al. 2011), and the representation of deep convection in the Sahel and its effects on the WAM (Garcia-Carreras et al. 2013; Marsham et al. 2013; Birch et al. 2014). Particularly, biases in sea surface temperatures (SSTs) have a large effect on precipitation and the WAM circulation (Biasutti et al. 2008; Hourdin et al. 2010; Roehrig et al. 2013; Paxian et al. 2016). Moreover, Marsham et al. (2013) and Birch et al. (2014) show that issues in the diurnal cycle of latent heating and cloud radiative forcing impact on the north-south pressure gradient and thus the northward advection of moisture from the south to the Sahel.

One element of the WAM that has received relatively little attention so far is the extensive cover of low- and midlevel clouds over southern West Africa (SWA) during the peak summer monsoon from July to September (JAS) (Knippertz et al. 2011). This period, when precipitation is relatively sparse but stratiform clouds are abundant, is called the "little dry season" in this area. The dominant cloud type is very low-level stratus that often forms near the Guinea Coast in the evening hours and then spreads northward in the course of the night, reaching a maximum extension around 09001000 LT (Schuster et al. 2013; van der Linden et al. 2015). The clouds then lift and break open into fair weather cumuli that occasionally grow deep enough to produce significant precipitation. Through the strong contrast in brightness to the underlying densely vegetated areas, the low clouds have a substantial impact on the radiation balance at the surface and therefore determine the diurnal cycle of the planetary boundary layer (PBL) (e.g., Gounou et al. 2012). Related changes in surface gradients of equivalent potential temperature may have an impact on larger scales. For example, Zheng and Eltahir (1998) showed that the greatest sensitivity in their idealized Hadley cell model was related to land surface perturbations in SWA, not in the Sahel.

Because of the low thermal contrast with the cloudfree surface, a detection of the stratus decks at night is challenging and many existing cloud products show an underestimation of cloud fraction (Knippertz et al. 2011). Recently, van der Linden et al. (2015) developed a comprehensive climatology based on brightness temperature differences in three infrared channels of the Spinning Enhanced Visible and Infrared Imager (SEVIRI) onboard the Meteosat Second Generation (MSG) satellites. Despite problems with overlapping higher clouds and discrepancies between different satellite sensors, these authors revealed a local maximum over Ivory Coast and upwind of the Mampong Range (Ghana) and the Oshogbo Hills (Nigeria) (see Fig. 1 for locations). The satellite estimates are broadly consistent with human observations from SYNOP weather stations, which indicate an average morning cover of low clouds well above 50\% (Schrage and Fink 2012; van der Linden et al. 2015).

Several studies have discussed mechanisms that control the formation and dissolution of the cloud decks, which typically form underneath the core of the nocturnal low-level jet (LLJ). This jet depends on the monsoonal north-south pressure gradient and the acceleration due to ceasing turbulent friction during the night, typically creating maximum wind speeds a few hundred meters above ground in the early morning hours (Parker et al. 2005; Lothon et al. 2008; Abdou et al. 2010; Gounou et al. 2012; Schrage and Fink 2012). 
Using high-resolution simulations Schuster et al. (2013) show that the LLJ transports cooler but also drier air inland. More cooling is caused by outgoing longwave radiation, either from the surface before cloud formation or from cloud top afterward. If radiative cooling is anomalously strong, the surface layer can become decoupled from the lower troposphere, impeding cloud formation (Schrage et al. 2007). Depending on vertical stability, which in turn depends on differential temperature advection and radiative cooling, shear-generated turbulent fluxes of heat and moisture can support cloud formation (Schrage and Fink 2012). This is consistent with a spreading of turbulent kinetic energy and clouds inland in the course of the night (Schuster et al. 2013), which is not a purely advective effect, as the spreading occurs faster than the wind in the LLJ core (Schuster et al. 2013; van der Linden et al. 2015). Schrage et al. (2007) found a strong southwesterly monsoon flow for cloudy nights at Parakou, suggesting that effects of vertical mixing and cold advection dominate over those of dry advection. Additional factors are moderate temperature tendencies from condensation and evaporation, as well as orographic lifting, causing maxima on windward sides of small hill ranges (van der Linden et al. 2015).

With respect to the representation of the low clouds over SWA in global climate models, Knippertz et al. (2011) provided a comprehensive analysis of data from phase 3 of the Coupled Model Intercomparison Project (CMIP3). In comparison to satellite data and short-term forecasts from the European Centre for Medium-Range Weather Forecasts (ECMWF), this study revealed positive biases in LLJ speed, negative biases in low-level cloud cover, and therefore a large overestimation of solar radiation during the day. The LLJ biases, which should also affect advection and turbulent mixing, are consistent with biases in the north-south pressure gradient due to the misrepresentation of convection in the Sahel (Marsham et al. 2013). For the more recent CMIP5 dataset, Roehrig et al. (2013) found large cloudrelated shortwave radiative errors over SWA, but a more even spread of models across negative and positive biases. In an idealized single-column model study Couvreux et al. (2014) show that a feedback loop between low clouds, shortwave radiation, temperature, and saturation can create a considerable cold bias within less than a day. For adjacent oceanic regions, Nam et al. (2012) discuss problems of CMIP5 models with cloud coverage and cloud brightness.

The present study has two main goals. The first is to repeat the analysis by Knippertz et al. (2011) with the more recent CMIP5 data. As the focus is on processes over land, only simulations with prescribed SSTs
[Atmospheric Model Intercomparison (AMIP)-type experiments] will be considered. The second goal is to better understand the physical mechanisms behind the identified model errors. New global simulations made in the framework of the Year of Tropical Convection (YoTC) offer some exciting new opportunities in this regard due to the availability of four times daily data (analysis of diurnal cycle) and of contributions to local temperature and moisture tendencies from parameterized processes such as radiation, turbulent mixing, and convection.

The paper will start with a description of the observational and model data, as well as the methods used in this study (section 2). Results for CMIP5 will be shown in section 3 and those for YoTC data in section 4. Both will investigate the representation of low-level cloudiness and wind, but section 4 will look much more deeply into physical mechanisms. Conclusions from both parts will be summarized in section 5 , followed by a short discussion of open questions for future work.

\section{Data and methods}

\section{a. Model and reanalysis data}

\section{1) CMIP5}

The CMIP5 models form the basis of the Fifth Assessment Report of the Intergovernmental Panel on Climate Change (IPCC). A number of different experiments were conducted (Taylor et al. 2012), but for this study only the historical AMIP simulations from 1979 to 2008 were chosen. All models were forced with the same SSTs, such that differences will be mainly caused by discrepancies in atmospheric dynamics, possibly enhanced over SWA by different representations of soil and vegetation characteristics (e.g., Paxian et al. 2016). The 18 CMIP5 models, for which daily cloud data are available, are listed in Table 1 . They differ in their horizontal and vertical resolution, with grid spacings ranging between $0.25^{\circ}$ and $2.8125^{\circ}$ and from 18 to 95 vertical levels. For better comparison, model data were bilinearily interpolated to a common grid with $1.5^{\circ}$ grid spacing. As the focus of this study is on low levels, the numbers of model levels below $700 \mathrm{hPa}$ are also given in Table 1, ranging from 5 to 19 . Output frequency varies from model to model and depends on the meteorological variable, but data typically come in the form of daily or monthly means.

\section{2) YoTC}

To address specific challenges related to simulating prominent phenomena of the tropical atmosphere, the 
TABLE 1. List of used CMIP5 climate models that provide data on cloud fraction. Provided are the model name, main institution running the model, horizontal resolution on a latitude-longitude grid, total number of vertical levels, vertical levels below $700 \mathrm{hPa}$, and main literature reference. (For expansions of acronyms, see http://www.ametsoc.org/PubsAcronymList.)

\begin{tabular}{|c|c|c|c|c|c|}
\hline Model & Institute & Lat $\times$ lon & Lev & $\geq 700 \mathrm{hPa}$ & References \\
\hline BCC-CSM1.1 & $\begin{array}{l}\text { Beijing Climate Center, China Meteorologi- } \\
\text { cal Administration }\end{array}$ & $2.8125 \times 2.8125$ & 26 & 5 & Wu et al. (2010) \\
\hline BNU-ESM & Beijing Normal University & $2.8125 \times 2.8125$ & 26 & 5 & Ji et al. (2014) \\
\hline CCSM4 & $\begin{array}{l}\text { U.S. National Center for Atmospheric Re- } \\
\text { search (NCAR) }\end{array}$ & $1.25 \times 1.25$ & 26 & 5 & Gent et al. (2011) \\
\hline CMCC-CM & $\begin{array}{l}\text { Centro Euro-Mediterraneo per I Cambia- } \\
\text { menti Climatici }\end{array}$ & $0.75 \times 0.75$ & 31 & 9 & Scoccimarro et al. (2011) \\
\hline CNRM-CM5 & $\begin{array}{l}\text { Centre National de Recherches Météor- } \\
\text { ologiques and Centre Européen de Re- } \\
\text { cherche et de Formation Avancée en } \\
\text { Calcul Scientifique }\end{array}$ & $1.406 \times 1.406$ & 31 & 9 & Voldoire et al. (2013) \\
\hline CSIRO-Mk3.6.0 & $\begin{array}{l}\text { Queensland Climate Change Centre of Ex- } \\
\text { cellence and Commonwealth Scientific and } \\
\text { Industrial Research Organization }\end{array}$ & $0.875 \times 0.875$ & 18 & 6 & Rotstayn et al. (2012) \\
\hline EC-EARTH & $\begin{array}{l}\text { Irish Centre for High-End Computing } \\
\text { (ICHEC) }\end{array}$ & $1.125 \times 1.125$ & 62 & 19 & Hazeleger et al. (2012) \\
\hline FGOALS-s2 & $\begin{array}{l}\text { The State Key Laboratory of Numerical } \\
\text { Modeling for Atmospheric Sciences and } \\
\text { Geophysical Fluid Dynamics, The Institute } \\
\text { of Atmospheric Physics }\end{array}$ & $1.67 \times 2.8125$ & 26 & 5 & Bao et al. (2013) \\
\hline FGOALS-g2 & $\begin{array}{l}\text { LASG (Institute of Atmospheric Physics) } \\
\text { CESS (Tsinghua University) }\end{array}$ & $1.67 \times 2.8125$ & 26 & 5 & Li et al. (2012) \\
\hline GFDL-CM3 & $\begin{array}{l}\text { NOAA Geophysical Fluid Dynamics } \\
\text { Laboratory }\end{array}$ & $2 \times 2.5$ & 48 & 12 & Donner et al. (2011) \\
\hline $\begin{array}{l}\text { GFDL-HIRAM- } \\
\text { C360 }\end{array}$ & $\begin{array}{l}\text { NOAA Geophysical Fluid Dynamics } \\
\text { Laboratory }\end{array}$ & $0.25 \times 0.3125$ & 32 & 12 & Donner et al. (2011) \\
\hline GISS-E2-R & $\begin{array}{l}\text { NASA Goddard Institute for Space Studies } \\
\text { (GISS) }\end{array}$ & $2 \times 2.5$ & 29 & 9 & Schmidt et al. (2014) \\
\hline INM-CM4 & Russian Institute for Numerical Mathematics & $1.5 \times 2$ & 21 & 6 & Volodin et al. (2010) \\
\hline IPSL-CM5A-MR & Institut Pierre Simon Laplace & $1.27 \times 2.5$ & 39 & 9 & Dufresne et al. (2012) \\
\hline MIROC5 & $\begin{array}{l}\text { University of Tokyo, National Institute for } \\
\text { Environmental Studies, and Japan Agency } \\
\text { for Marine-Earth Science and Technology }\end{array}$ & $1.4 \times 1.4$ & 40 & 13 & Watanabe et al. (2010) \\
\hline MPI-ESM-MR & Max Planck Institute for Meteorology & $1.875 \times 1.875$ & 95 & 9 & Stevens et al. (2012) \\
\hline MRI-CGCM3 & Meteorological Research Institute (MRI) & $1.125 \times 1.125$ & 35 & 10 & Yukimoto et al. (2012) \\
\hline NorESM1-M & Norwegian Climate Centre & $1.8947 \times 2.5$ & 26 & 5 & Iversen et al. (2013) \\
\hline
\end{tabular}

World Climate Research Program (WCRP) and The Observing System Research and Predictability Experiment (THORPEX) of the World Weather Research Program (WWRP) jointly implemented a coordinated research program referred to as YoTC (Waliser et al. 2012). The main YoTC focus period runs from May 2008 to April 2010. As a joint research activity between GEWEX Atmosphere System Study (GASS) and YoTC, the Vertical Structure and Physical Processes Multimodel Experiment was conducted using 24 global atmospheric models (Jiang et al. 2015, their Table 1). Here we use 20-yr climate simulations covering the period 1991-2010. All models use weekly SSTs and sea ice concentrations based on the NOAA Optimum Interpolation V2 product (Reynolds et al. 2002) as lower boundary conditions and prescribed aerosols. Despite different native resolutions, output was archived every $6 \mathrm{~h}$ on a standard horizontal $\left(2.5^{\circ} \times 2.5^{\circ}\right)$ grid with 22 vertical pressure levels (nine below $700 \mathrm{hPa}$ ). Unfortunately only eight of the YoTC models provide all the output necessary for the analysis in this paper. Two of these are not used in CMIP5: (a) the GEOS5 model run by the Global Modeling and Assimilation Office of the National Aeronautics and Space Administration (NASA) on a $0.5^{\circ} \times 0.625^{\circ}$ lat-lon grid with 72 vertical levels (Molod et al. 2012) and (b) the NavGEM1 model run by the U.S. Naval Research Laboratory in T359 spectral resolution (corresponds to about $37 \mathrm{~km}$ ) with 42 vertical levels [similar to NavGEM1.1 described in Hogan et al. (2014)]. The other six models use configurations similar or identical to their CMIP5 counterparts and are listed below: 
1) The CAM5 model run by NCAR (Neale et al. 2012) and the CAM5-ZM run by the Lawrence Livermore National Laboratory (Song and Zhang 2011) are both based on CCSM4 but have different modifications. Their horizontal lat-lon grid of $0.9^{\circ} \times 1.25^{\circ}$ with 30 vertical levels is a little finer than that of CCSM4 (Table 1).

2) CNRM-AM is the atmosphere-only version of the coupled model CNRM-CM5 $\left(1.406^{\circ} \times 1.406^{\circ}, 31\right.$ vertical levels).

3) FGOALS-s2 is the same model version as used in CMIP5 $\left(1.67^{\circ} \times 2.8125^{\circ}, 26\right.$ vertical levels $)$.

4) The GISS-E2 model run by NASA/GISS is the atmosphere-only version of GISS-E2-R $\left(2^{\circ} \times 2.5^{\circ}\right)$ and has 40 instead of 29 vertical levels. Some modifications specific for improvement of the MaddenJulian oscillation as discussed in Kim et al. (2012) were also applied in YoTC.

5) The MRI-AGCM3 model run by MRI is the atmosphere-only version of MRI-CGCM3 $\left(1.12^{\circ} \times\right.$ $\left.1.125^{\circ}\right)$ and has 48 instead of 35 vertical levels.

YoTC model fields used here are cloud area fraction, wind, temperature $(T)$, specific humidity $(q)$, pressure $(p)$, and surface net solar radiation as well as tendencies of $q$ and $T$. Relative humidity (RH) was computed according to $\mathrm{RH}=e / E$, where $e$ is water vapor pressure and $E$ saturation vapor pressure, using

$$
\begin{aligned}
e & =\frac{q}{0.378 q+0.622} p, \\
E & =6.112 \exp \left[17.62 T(243.12+T)^{-1}\right] .
\end{aligned}
$$

A key parameter analyzed here is low-level cloud cover, which is strongly controlled by the subgrid cloud scheme. To illustrate the range of schemes used, the online supplementary material (SM) provides short summaries for each YoTC model. A detailed analysis of the effect of the different approaches on clouds over SWA, however, is beyond the scope of this paper.

Tendencies of $T$ and $q$ due to advection are abbreviated tnTadv and tnqadv, respectively. Tendencies due to parameterized processes are treated differently across the various models. They were combined into three groups in order to facilitate comparisons:

1) Radiative processes: This includes shortwave and longwave components and only affects temperature, usually cooling at night and heating during the day (tendency tnTrad).

2) Convective processes: This includes effects of shallow and deep convection as well as grid-scale clouds and precipitation. Typically these processes result in drying and cooling of low levels and moistening and heating of upper levels through vertical transports, latent heating, and evaporative cooling (tendencies tnTcon and tnqcon, respectively).

3) Diffusional processes: This includes vertical mixing from turbulent processes and diffusion (natural and numerical), typically depending on vertical gradients and stability (tendencies tnTdiff and tnqdiff, respectively).

The effect of each of these processes on low-level cloud formation will be analyzed in section $4 \mathrm{~b}$. Unfortunately, a number of inconsistencies or errors were discovered in the course of the data analysis. For MRIAGCM3, GISS-E2, GEOS5, CAM5-ZM, and CAM5 wind fields in the bottom layer show unrealistic values, probably due to extrapolation from model to pressure levels, and were therefore excluded from the analysis. GEOS5 has no tendency data for 1995 and 1996; for FGOALS-s2 1991 is missing. For MRI-AGCM3, the time stamps for radiation and tendency terms were inconsistent with the other models and needed to be corrected. For example, the radiation values for 0600 UTC are representative for the period 0600-1200 UTC, not 0000-0600 UTC as usual. The tendency terms are instantaneous but also appear to be mislabeled with the preceding time step.

\section{3) ERA-INTERIM}

As an observational reference short-term forecasts starting at 0000 UTC generated as part of the production process of the ERA-Interim (ERA-I) reanalysis (Dee et al. 2011) were used in a temporal resolution of $6 \mathrm{~h}$ (i.e., forecast hours $+0600,+1200,+1800$, and +2400 ) on a $0.75^{\circ} \times 0.75^{\circ}$ horizontal grid. These data were chosen instead of the actual reanalysis for consistency with Knippertz et al. (2011) and because model fields such as surface solar radiation are not directly analyzed but derived as 6-hourly accumulated values from short-term forecasts anyway. ERA-I has 16 (19) model levels below $700(600) \mathrm{hPa}$. For consistency with the climate models, RH was computed according to Eqs. (1) and (2). Data are available from 1979 onward and thus cover both the CMIP5 and YoTC periods investigated here. As a caveat, there are nonnegligible differences in low-level cloudiness between the short-term forecasts used here and the actual reanalysis, which has fewer clouds during the night and more at midday (not shown). This surprising behavior of the ECMWF model deserves a more detailed investigation, which goes beyond the scope of this paper. It should also be kept in mind that ERA-I relies heavily on the employed numerical model and that therefore different reanalysis products can differ considerably in areas with few observations (Roehrig et al. 2013; Roberts et al. 2015). 
For JAS 2008 and 2009, which are included in the YoTC focus period (see section 2a), 1200 UTC shortterm forecasts with additional output fields were carried out with a post-ERA-I version of the ECWMF forecast system. These include 3-hourly accumulated tendencies of $q$ and $T$. To allow for a comparison with instantaneous tendencies from the YoTC climate models, 6-hourly time windows centered on the YoTC times were computed. Using forecasts started at 1200 UTC, tendencies for $1800 \mathrm{UTC}$ are obtained by subtracting the forecast for 1500 UTC $(+3 \mathrm{~h})$ from that for 2100 UTC $(+9 h)$ divided by six hours and so on until forecast hour +27 . We compared YoTC tendencies for the full period available (1991-2010) with a subsample to 2008 and 2009 and did not find significant differences, suggesting that the comparisons with ERA-I tendencies derived from two seasons only are meaningful (not shown).

\section{b. Surface and satellite observations of solar radiation}

Long-term station measurements of incoming solar radiation to validate models are infrequent across SWA. Therefore here we use all available data from 15 stations in total in Nigeria, Benin, Ghana, and the Ivory Coast irrespective of the exact periods (see SM), assuming that the obtained climatologies give reasonable estimates of typical values and therefore allow evaluating models and satellite products. Minimum coverage is 5 years (Axim, Ghana) but most stations have substantially more data.

For a gridded observational estimate and its uncertainty, two different Satellite Application Facility on Climate Monitoring (CM SAF) products for satellitederived surface solar radiation were considered. Used here are monthly mean data with a horizontal resolution of $0.05^{\circ} \times 0.05^{\circ}$. Surface downwelling shortwave radiation from the Surface Solar Radiation Dataset-Heliosat (SARAH; Müller et al. 2015) was derived from the Meteosat Visible and Infrared Imager (MVIRI) and SEVIRI instruments on-board geostationary Meteosats 4-9 covering the period 1983-2008. The derivation is based on a retrieval using the Heliosat approach and an efficient clear-sky surface solar radiation transfer model (Mueller et al. 2009; Posselt et al. 2012). The second dataset is the operational downwelling surface shortwave radiation derived using SEVIRI and Geostationary Earth Radiation Budget (GERB) measurements during 2007-15. The algorithm is based on a look-up table approach to derive the atmospheric transmission for cloudfree as well as cloudy sky (Mueller et al. 2009).

The main difference between the two datasets is the temporal consistency of the applied algorithms. SARAH was produced using a single algorithm, while the operational version undergoes regular updates and is therefore not strictly homogeneous. Moreover, for SARAH the effective cloud albedo is derived from SEVIRI, which is then used to estimate the solar irradiance applying the MAGIC lookup table. The first step is self-calibrating, since it scales the original satellite counts of SEVIRI or MVIRI, respectively, to derive the effective cloud albedo. This step is omitted in the operational version. Instead, the solar irradiance is derived using top-of-atmosphere albedo from GERB and SEVIRI as input for MAGIC. Both datasets also use aerosol information for their estimates, the quality of which is hard to assess for our region of interest.

\section{c. Methods}

\section{1) Averaging}

The focus of this study is on SWA and therefore many of the fields examined are averaged over the region $5^{\circ}-$ $10^{\circ} \mathrm{N}, 8^{\circ} \mathrm{W}-8^{\circ} \mathrm{E}$ (red box in Fig. 1). This region is slightly larger than that used by Knippertz et al. (2011) (i.e., $6^{\circ}-$ $\left.10^{\circ} \mathrm{N}, 7^{\circ} \mathrm{W}-7^{\circ} \mathrm{E}\right)$. All data were vertically interpolated to the pressure levels $1000,975,950,925,900,850,800,750$, 700,650 , and $600 \mathrm{hPa}$. As advection was not directly output in CMIP5, it was calculated here from wind, $T$, and $q$ fields. First all CMIP5 data were bilinearly interpolated to the same horizontal grid with spacings of $1.5^{\circ}$. As most of the horizontal transport is from the south into the averaging box, fixed latitudes near the Guinea Coast were chosen (see black lines in Fig. 1). Meridional gradients were computed between $4.5^{\circ}$ and $7.5^{\circ} \mathrm{N}$, and winds were taken at $6.0^{\circ} \mathrm{N}$. Afterward the results were averaged zonally from $8^{\circ} \mathrm{W}$ to $8^{\circ} \mathrm{E}$. These values will be discussed in section 3 . Tests with other latitudes show moderate sensitivity to the exact choice of area.

One problem in the comparison between the datasets considered here are the different temporal resolutions (6-hourly for ERA-I and YoTC, and mostly monthly means for CMIP5). While scalar values such as cloud fraction and temperature are uncritical, parameters derived from vectors are affected. Therefore, for the wind speed and advection computations shown in Fig. 2 monthly means of $T, q$, and wind were first computed from ERA-I to be fully comparable to the CMIP5 model output. To estimate the impact of time averaging, some simple tests with ERA-I were conducted. For wind speed, computing long-term averages from monthly means of the zonal and meridional components instead of using instantaneous values results in insignificant reductions (around $5 \%$ ) below $900 \mathrm{hPa}$ due to the stability of the monsoon flow, but deviations grow substantially between 800 and $700 \mathrm{hPa}$ (up to $53 \%$ in some cases). Above this level, where stable easterly flow prevails, the differences decrease again. For advection, differences 

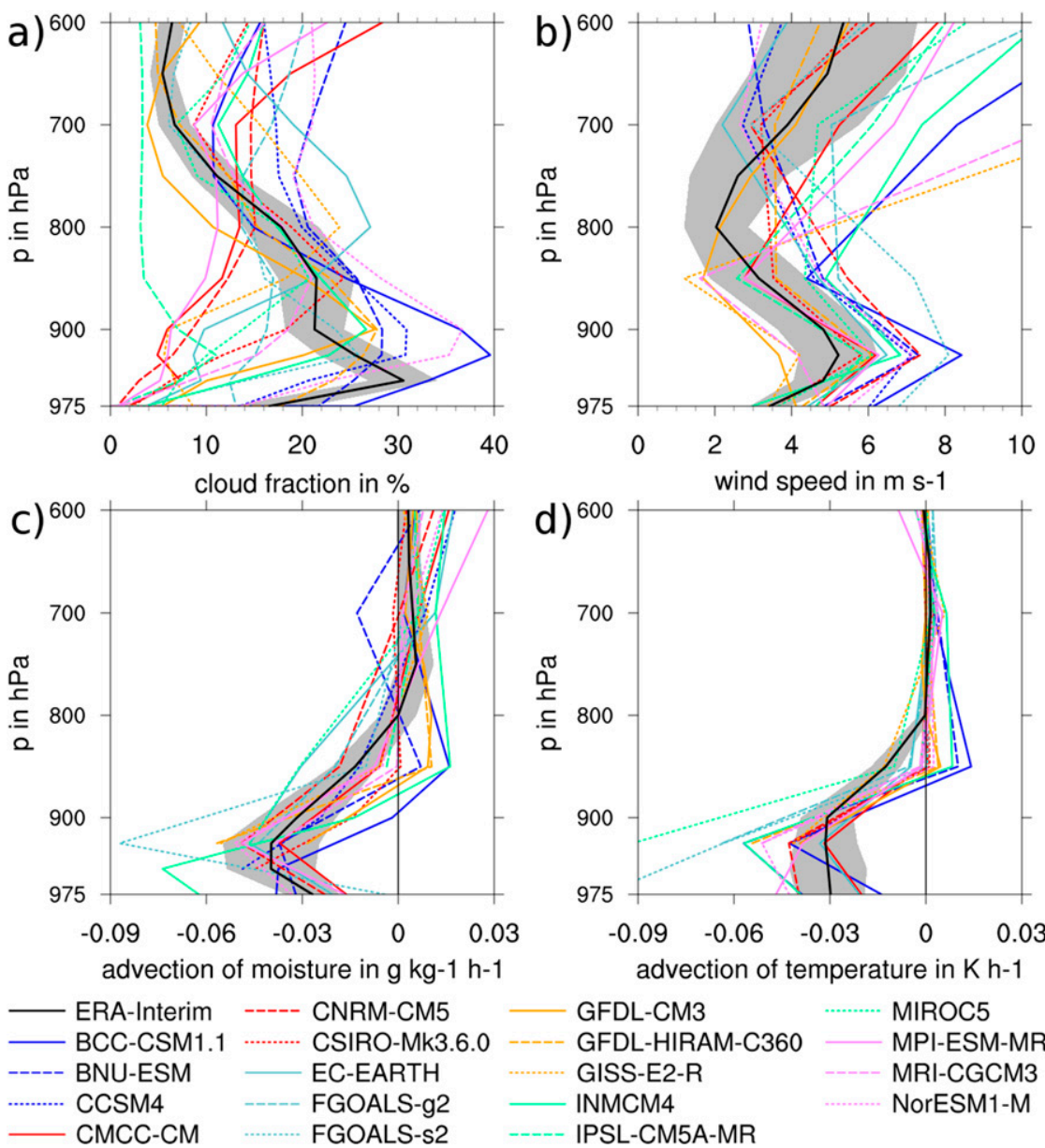

PSL-CM5A-MR

FIG. 2. Lower-tropospheric profiles for CMIP5 models and ERA-I: (a) cloud fraction, (b) wind speed, (c) advection of moisture, and (d) advection of temperature. All data are spatially averaged over the red box shown in Fig. 1 and temporally over JAS 1979-2008. The gray shading shows the standard deviation of monthly mean ERA-I profiles. The wind speed and advection terms are computed from monthly means of $T, q$, and wind, using the latitudes indicated with black lines in Fig. 1. For some models, advection could not be computed for $975 \mathrm{hPa}$, as this level is partly below the model orography. See section $2 \mathrm{c}$ for more details.

are generally less than $1 \%$ due to the additional effect of the stable gradients in $T$ and $q$ in the SWA region.

\section{2) Tendencies of RelAtive HUMIDITY}

As subgrid-scale cloud cover typically depends on $\mathrm{RH}$ only in global climate models (e.g., Quaas 2012), a focus will be put on different contributions to the tendencies of RH. For a constant-pressure level these can be calculated directly from the tendencies of $T$ and $q$ through

$$
\begin{aligned}
\frac{\partial \mathrm{RH}}{\partial t}= & \frac{\partial \frac{e}{E}}{\partial t}=\frac{1}{E} \frac{\partial e}{\partial t}-\frac{e}{E^{2}} \frac{\partial E}{\partial t}=\frac{1}{E} \frac{\partial e}{\partial q} \frac{\partial q}{\partial t} \\
& -\frac{e}{E^{2}} \underbrace{\frac{\partial E}{\partial T}}_{\text {term } 1} \frac{\partial T}{\partial t} .
\end{aligned}
$$

Using the Clausius-Clapeyron equation for term 1 results in

$$
\frac{\partial \mathrm{RH}}{\partial T}=\frac{1}{E} \underbrace{\frac{\partial e}{\partial q}}_{\text {term } 2} \frac{\partial q}{\partial t}-\frac{e L}{R_{v} T^{2} E} \frac{\partial T}{\partial t},
$$

where $L$ is the heat of phase transformation $(2.5 \times$ $10^{6} \mathrm{~J} \mathrm{~kg}^{-1}$ ), and $R_{v}$ is the specific gas constant of water vapor [461.51 $\left.\mathrm{J}(\mathrm{kg} \mathrm{K})^{-1}\right]$. Using Eq. (1), term 2 yields

$$
\begin{aligned}
\frac{\partial e}{\partial q} & =p\left[\frac{1}{0.378 q+0.622}-q \frac{0.378}{(0.378 q+0.622)^{2}}\right] \\
& =p\left[\frac{0.622}{(0.378 q+0.622)^{2}}\right] .
\end{aligned}
$$


Inserting Eqs. (1) and (5) into Eq. (4), the tendency of $\mathrm{RH}$ can be calculated from $p$ and the absolute values and time tendencies of $T$ and $q$ :

$$
\begin{aligned}
\frac{\partial \mathrm{RH}}{\partial t}= & \frac{p}{E}\left[\frac{0.622}{(0.378 q+0.622)^{2}} \frac{\partial q}{\partial t}\right. \\
& \left.-\frac{q L}{(0.378 q+0.622) R_{v} T^{2}} \frac{\partial T}{\partial t}\right] .
\end{aligned}
$$

\section{Results for CMIP5}

Figure 2 shows vertical profiles of cloud fraction, wind speed, and advection of $q$ and $T$, averaged over SWA for the 18 CMIP5 models (colors) and ERA-I (black) for JAS 1979-2008. With regard to cloud cover, ERA-I features a clear maximum of $30 \%$ at $950 \mathrm{hPa}$. Cloud cover then decreases to $20 \%$ between 900 and $850 \mathrm{hPa}$, followed by a marked decline toward $700 \mathrm{hPa}$ (Fig. 2a). The 950-hPa maximum is similar to that shown in Fig. 3b of Knippertz et al. (2011). The small differences are due to changes in averaging box and time period (1979-2008 vs 1989-2010). Hardly any of the global CMIP5 climate models reproduce the near-surface peak in cloudiness (Fig. 2a). Some models show at least peaks around 925900 hPa (e.g., CCSM4, NorSM1-M, GFDL-CM3, BNUESM), but others have maxima as high as $800 \mathrm{hPa}$ (e.g., EC-Earth, GISS-E2-R). Values range from hardly any low clouds to significant overestimation with maxima up to $40 \%$, consistent with the biases in shortwave radiation and clouds found by Roehrig et al. (2013). Most models underestimate low-level cloudiness by much more than the monthly standard deviations in ERA-I shown in gray shading in Fig. 2a. Relative to CMIP3 (Knippertz et al. 2011), the spread in cloud cover and wind is slightly reduced, and the overall bias in low-level cloudiness is not as negative.

With respect to wind speed (Fig. 2b), ERA-I clearly shows the LLJ peaking around $925 \mathrm{hPa}$ with just over $5 \mathrm{~m} \mathrm{~s}^{-1}$, followed by a minimum at $800 \mathrm{hPa}$ and another increase into the layer of mean easterlies. Many CMIP5 models correctly simulate an LLJ maximum around $925 \mathrm{hPa}$, but overestimate wind speed through large parts of the lower troposphere. MRI-CGCM3 and GISS-E2-R show weak winds at low levels and very large positive biases aloft, indicating substantial problems with the overall WAM circulation. Again there is at best small improvement relative to CMIP3 (Knippertz et al. 2011).

With regard to $q$ advection (Fig. 2c), ERA-I shows negative values below $800 \mathrm{hPa}$ consistent with the highresolution modeling experiments by Schuster et al. (2013). The dry air advection can be understood by an increase in $q$ in the lower troposphere from the equatorial Atlantic Ocean northward toward the maximum rainfall zone over West Africa along $10^{\circ} \mathrm{N}$ in combination with the steady southwesterly monsoonal flow in this layer. The drier air over the ocean is related to subsidence over relatively cool waters. Above $800 \mathrm{hPa}$, a layer of moist advection exists, probably related to a weak northerly component at this level, which may transport moister air from the main rain belt into our study area (Zhang et al. 2008). All climate models show a peak at $925 \mathrm{hPa}$ as in ERA-I but overestimate its magnitude. This result appears broadly consistent with the models' behavior in cloud cover (Fig. 2a). For example, CNRM-CM5 shows too strong dry advection related to a too strong LLJ and thus too little cloud cover. Nevertheless there is a considerable intermodel spread in behavior.

ERA-I shows significant cold advection below $900 \mathrm{hPa}$ and a marked decrease toward $800 \mathrm{hPa}$ (Fig. 2d). Cold air advection can support low-cloud formation by reduction of the saturation deficit and, if increasing with height, by destabilization of near surface layers resulting in vertical mixing (Schuster et al. 2013). All climate models overestimate the cold advection consistent with their overestimation of the LLJ (Fig. 2b). There is no obvious correspondence between the cold and dry advection behavior of the models. These results suggest that in some models the strong cold advection must be counteracted by other processes to avoid extensive cloud formation. This will be investigated in more detail in section 4.

\section{Results for YoTC}

In this section, output from the YoTC models will be analyzed and compared to those for the CMIP5 models discussed in section 3. A first great advantage of the YoTC dataset is the four times daily output that allows a crude analysis of the diurnal cycle (section 4a). The second great advantage of YoTC is the availability of tendency terms for $T$ and $q$, which are analyzed in section $4 \mathrm{~b}$. This allows a much better understanding of model biases.

\section{a. Diurnal cycle}

This subsection discusses the diurnal cycle in low cloudiness and wind within the YoTC dataset, differences between YoTC and CMIP5 model versions, and the impact of the low clouds on radiation.

\section{1) VerticAl PROFiles}

Figure 3 shows vertical profiles across the lower troposphere of cloud area fraction (top), wind speed 

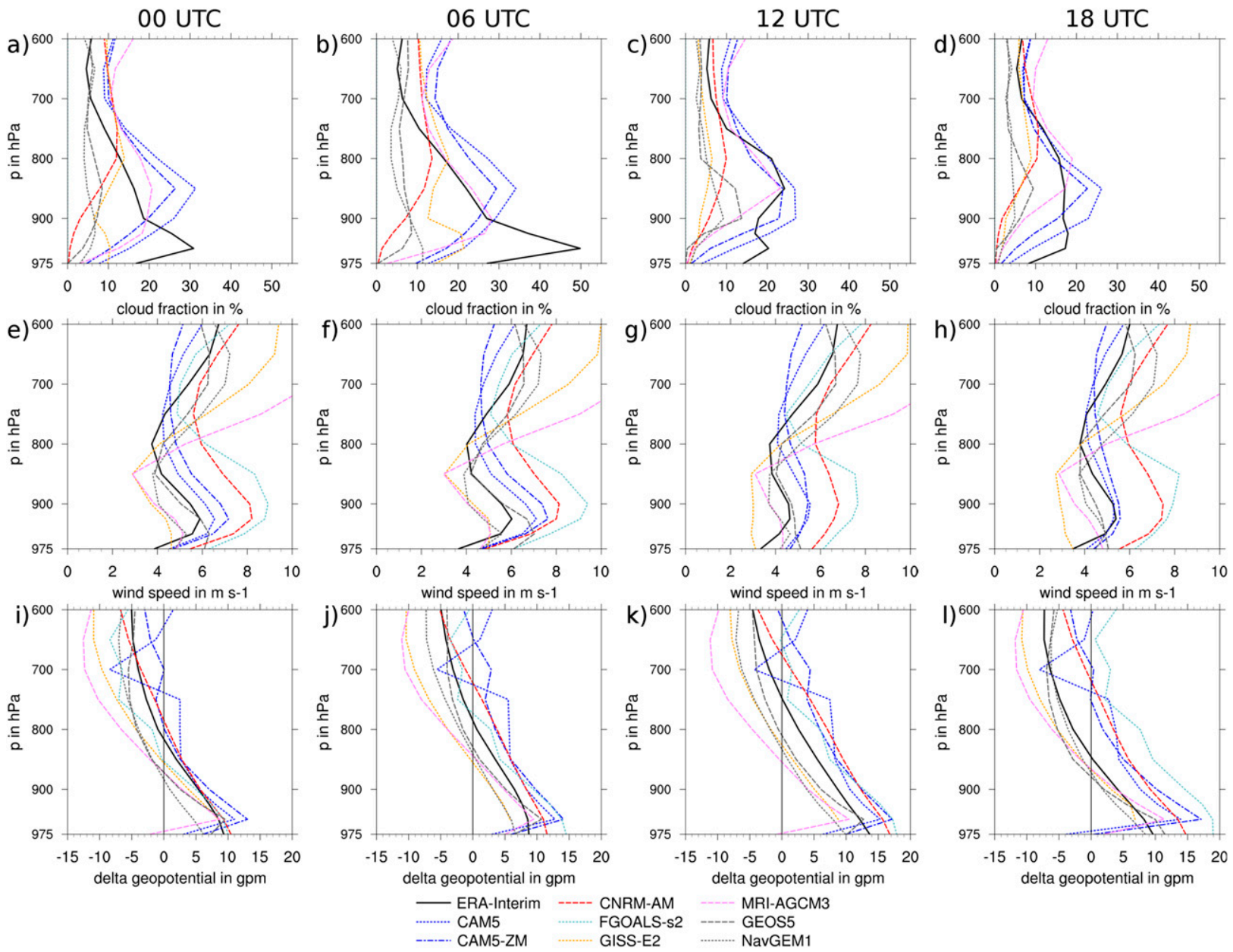

FIG. 3. Diurnal cycle in lower-tropospheric profiles for YoTC models and ERA-I: (top) cloud fraction, (middle) wind speed, and (bottom) difference of geopotential height between $5^{\circ}$ and $10^{\circ} \mathrm{N}$, at (left to right) 0000, 0600,1200, and 1800 UTC. Wind and cloud data are spatially averaged over the red box shown in Fig. 1, and geopotential height differences over its zonal extension. All data are means over JAS 1991-2010.

(middle), and south-north difference of geopotential height (bottom) for ERA-I (black) and the eight YoTC models. The first two variables are averaged spatially across the red box shown in Fig. 1. The differences in geopotential height are computed at the southern $\left(5^{\circ} \mathrm{N}\right)$ and northern $\left(10^{\circ} \mathrm{N}\right)$ fringes of this box and are then averaged longitudinally.

With respect to low-level cloudiness, ERA-I shows first indications of nocturnal stratus formation at 0000 UTC with a maximum of $30 \%$ at $950 \mathrm{hPa}$ (Fig. 3a). This cloud layer grows until $0600 \mathrm{UTC}$, when it reaches $50 \%$ (Fig. 3b). In the course of the morning, the cloud deck lifts to $850 \mathrm{hPa}$, broadens vertically, and breaks open, reaching a maximum fraction of about $25 \%$ at 1200 UTC (Fig. 3c). Until 1800 UTC, the cloud layer continues to broaden vertically, leading to a reduced maximum of $18 \%$ at 1800 UTC (Fig. 3d). This diurnal cycle of low-level cloudiness explains the primary and secondary maxima at 950 and $850 \mathrm{hPa}$, respectively, in Fig. 2a. As is evident from Figs. 3a-d, none of the YoTC models reproduces the diurnal cycle in cloud cover in a realistic way. The overall largest cloud fractions are found for CAM5, but this model shows a stable maximum between 900 and $850 \mathrm{hPa}$ and small diurnal variations from $26 \%$ (1800 UTC) to $33 \%$ (0600 UTC). The CAM5-ZM from the same model family shows a similar behavior with a stable offset of about $-5 \%$ (Figs. 3a-d). The model that is overall closest to ERA-I is MRI-AGCM3, which shows a discernable diurnal cycle in height and extent of low clouds, and maxima not too dissimilar from the reanalysis. Nevertheless, even this model has too little cover of low clouds at 0600 UTC at a too high elevation (Fig. 3b) and then too elevated low clouds at 1800 UTC (Fig. 3d). The reasons for this behavior will be 
discussed in more detail in the following subsections. The remaining five YoTC models all have significantly too little cloud cover at all times. GISS-E2 and NavGEM1 stand out in that they show a nighttime cloud maximum at $950 \mathrm{hPa}$, somewhat similar to ERA-I but with much lower fractions (Figs. 3a,b). NavGEM1 and GEOS5 have elevated daytime maxima, which are too weak and too low compared with ERA-I (Fig. 3c). The CNRM-AM never exceeds $15 \%$ coverage at any level below $600 \mathrm{hPa}$ with maxima at $800 \mathrm{hPa}$ or above. Finally, FGOALS-s2 does not show any clouds at all below $600 \mathrm{hPa}$. This is likely a data error, but at least it is physically consistent with very low RH (see section 4b).

As discussed in the introduction and section 3, lowlevel wind is important for the stratus decks, as it controls advection of $T$ and $q$, and contributes to nighttime turbulent mixing. In ERA-I an LLJ is evident during the night, reaching $6 \mathrm{~m} \mathrm{~s}^{-1}$ at $925 \mathrm{hPa}$ at 0600 UTC (Figs. 3e,f). This value is realistic, as shown from radiosonde and profiler data (Schuster et al. 2013, their Fig. 4). Winds are slowed down by surface friction to $4.5 \mathrm{~m} \mathrm{~s}^{-1}$ at midday (Fig. 3g) and are already accelerating again at 1800 UTC, indicating a relatively early evening transition (Fig. 3h). The three YoTC models GISS-E2, MRI-AGCM3, and NavGEM1 tend to underestimate low-level winds throughout the day. GEOS5 stands out as a model that produces a jetlike vertical structure, but with slightly higher winds than ERA-I and even lower elevation. As with the clouds, CAM5-ZM and CAM5 show similar behavior with overall realistic jetlike structures and diurnal cycles but a slight overestimation of core wind speed. In agreement with the cloud fractions, CNRM-AM and FGOALS-s2 produce the largest disagreement with ERA-I, with jets that are much too strong and somewhat too high.

To investigate to what extent these deviations in wind are the result of local processes or the north-south pressure gradient, differences in geopotential height across the box are analyzed (Figs. 3i-1). As expected, ERA-I shows positive values throughout the lower troposphere with a maximum near the surface and a change of sign around $800 \mathrm{hPa}$. Maxima in near-surface values are largest at 1200 UTC, suggesting that the inland areas at $10^{\circ} \mathrm{N}$ heat up quicker than the cloudier coastal zone at $5^{\circ} \mathrm{N}$. The three YoTC models with the weakest winds (GISS-E2, MRI-AGCM3, and NavGEM1; see Figs. 3e-h) show a consistent, diurnally varying underestimation of the geopotential gradient, in particular NavGEM1, while GEOS5 agrees reasonably well with ERA-I for most of the day. The remaining four models (CAM5ZM, CAM5, CNRM-AM, and FGOALS-s2) overestimate the gradient in agreement with their wind fields, although the magnitude is not always consistent between the models. The fact that some models show a marked decrease between 950 and $975 \mathrm{hPa}$ could possibly be an artifact from extrapolating into orography but the authors were not able to find any details on how this is handled in YoTC output.

Remarkably, differences to ERA-I are generally larger at 1200 and 1800 UTC than at 0000 and 0600 UTC. Looking at the geopotential at $5^{\circ}$ and $10^{\circ} \mathrm{N}$ individually (not shown) reveals that all models but CNRM-AM and FGOALS-s2 show a weaker decrease of geopotential at $10^{\circ} \mathrm{N}$ between 0000 and 1200 UTC than ERA-I. At $5^{\circ} \mathrm{N}$ only GISS-E2 shows a decrease between 0000 and 1200 UTC similar to ERA-I, while all other models have weaker decreases or even increases. So in some cases (e.g., GEOS5) the errors compensate each other to give a realistic south-north difference. Possible reasons for this behavior are convective or radiative heating. The former idea was proposed by Marsham et al. (2013), who find that the well-known problem of many convection schemes to create an unrealistically early midday peak in precipitation leads to decreased pressure in the main rainband, with the real world catching up in the course of the night. This explanation is consistent with the models' precipitation fields that are mostly weaker than ERA-I at 1200 UTC (see supplementary Fig. S8 in the SM; see also Martin and Thorncroft 2015). A comparison of the YoTC models' zonal distribution of precipitation shows that there is some correspondence to the south-north difference in geopotential (Fig. S9 in SM). However, it must be noted here that ERA-I overestimates rainfall when compared to some satellite products, casting some doubt on the reliability of the reanalysis in this regard. Nevertheless, differences in radiation seem to be a less plausible explanation, as many models with too much surface solar radiation (see Fig. 4 and also Figs. S6 and S7 in the SM) also show too weak decreases in geopotential height. At least, this effect could compensate part of the differences in latent heating. Targeted sensitivity experiments would be needed to disentangle the details of these effects and possible feedbacks. It should also be noted here that there are nonnegligible differences in geopotential height between the actual ERA-I reanalysis and the short-term forecasts used here (not shown).

\section{2) CONSISTEnCy With CMIP5}

As six of the YoTC models (all but NavGEM1 and GEOS5) are used in CMIP5 in a similar version or configuration (section 2a), it is worth investigating the consistency in wind and cloud data (cf. Figs. 2 and 3). It should be kept in mind, however, that the CMIP5 and YoTC time periods differ slightly (1979-2008 vs 
a)

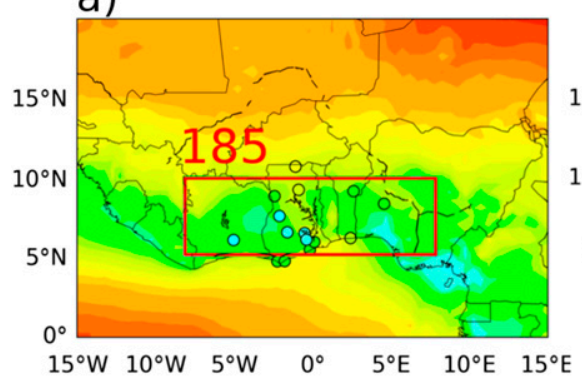

c)

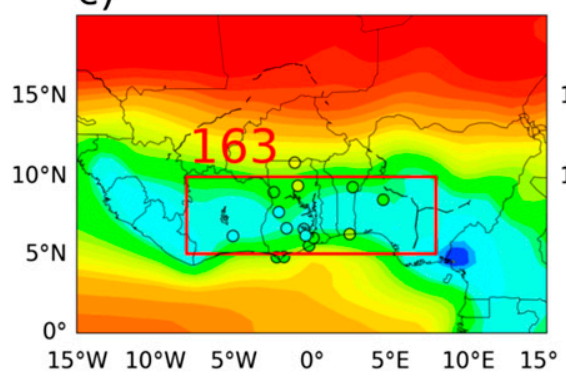

b)

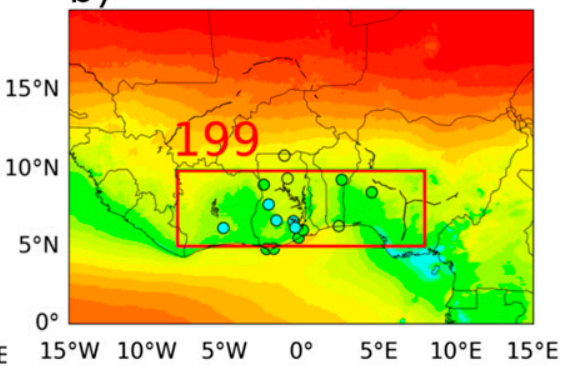

d)

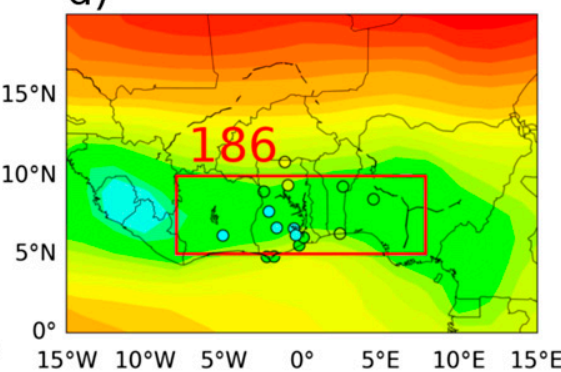

\section{$100 \quad 125 \quad 150 \quad 175 \quad 200 \quad 225 \quad 250 \quad 275 \quad 300$}

FIG. 4. Surface downwelling shortwave irradiance in $\mathrm{Wm}^{-2}$ : (a) $\mathrm{CM}$ SAF operational SEVIRI product, (b) CM SAF SARAH product, (c) ERA-I, and (d) mean over YoTC models. Climatologies from ground-based observations are depicted as circles. All data are temporally averaged over JAS but available periods differ: 2007-15 in (a), 1983-2008 in (b), and 1991-2010 in (c) and (d) with varying coverage for the stations (see the SM). Red boxes are as in Fig. 1 with spatial averages given at the top.

1991-2010), but this was tested not to be a significant factor (not shown).

For GISS-E2, CMIP5 data reveal a maximum of $24 \%$ at $800 \mathrm{hPa}$ and little cloud below $900 \mathrm{hPa}$ (Fig. 2a), while the YoTC version shows a nighttime maximum at $950 \mathrm{hPa}$ and substantially less cloud aloft (Figs. 3a-d). The wind profiles are more similar with LLJs of about $4 \mathrm{~m} \mathrm{~s}^{-1}$, but a more pronounced minimum at $850 \mathrm{hPa}$ in CMIP5 (Fig. 2b) than in YoTC (Figs. 3e-h). These deviations indicate that the modifications discussed in Kim et al. (2012) have a significant impact over West Africa, too, despite similar model resolution. The two related YoTC models CAM5 and CAM5-ZM show overall similar behavior, but some systematic offsets in both cloud and wind profiles (Figs. 3a-h). Comparing those with the slightly coarserresolution CMIP5 results from NCAR CCSM4 reveals similar wind structures but an even stronger overestimation in CMIP5 (Fig. 2b). Differences in clouds are more pronounced (cf. Fig. 2a with Figs. 3a-d) with CCSM4 having a maximum of about $33 \%$ at $925 \mathrm{hPa}$, while both YoTC model versions show maxima at $850 \mathrm{hPa}$ with values just below 30\% (CAM5) and around 25\% (CAM5-ZM). For MRI-AGCM3 cloud and wind profiles are largely consistent between the two datasets despite the better vertical resolution in YoTC. CNRM-AM and the CMIP5 version, CNRM CM5.1, both massively underestimate (overestimate) low-level clouds (winds) relative to ERA-I, but CNRM CM5.1 has a slightly larger maximum cloud cover at $800 \mathrm{hPa}$ (cf. Figs. 2a,b with Figs. 3a-h). As discussed above, the FGOALS-s2 model has no low clouds in YoTC at all. The fact that the corresponding model in CMIP5 (and also the related version G2) shows a profile in reasonable agreement with ERA-I (Fig. 2a; although without the vertical separation between the day- and nighttime maxima) suggests that this is in fact a data error. The two model versions consistently overestimate the jet relative to ERA-I (cf. Fig. 2b with Figs. 3e-h).

This short comparison suggests that conclusions derived from YoTC will likely hold for CMIP5 in the case of MRI-AGCM3, CNRM-AM, and FGOALS-s2, whereas for the other models differences in model formulation or resolution lead to more substantial deviations, which would require a more in-depth analysis of the causes.

\section{3) IMPACT ON RADIATION}

One motivation to study low-level clouds in SWA is their dominant impact on surface radiation, although of 
course mid- and higher-level clouds have some influence, too. Figure 4 shows long-term averages of surface downwelling shortwave irradiance from two satellite products, surface stations, ERA-I, and a mean over the eight YoTC models (see section 2b and the SM for more details). In all datasets irradiance shows maxima over the Sahara and equatorial Atlantic Ocean with a zonally elongated minimum over SWA reflecting the influence of the stratus. Some datasets at least also show local minima over the Guinea Highlands and Cameroon Mountains to the west and east of our study regions (marked with a red box in Fig. 4). A striking feature is the less cloudy area in the vicinity of Lake Volta in the observations.

Comparing satellite and station data reveals some reasonable agreement for the SEVIRI operational product for the northern stations, but a clear overestimation in the heart of the stratus belt over Ghana and Ivory Coast (Fig. 4a), suggesting that the area average of $185 \mathrm{~W} \mathrm{~m}^{-2}$ may be biased high. This problem gets worse when considering the SARAH product (Fig. 4b) that shows consistently higher values across the entire region with an area average of $199 \mathrm{~W} \mathrm{~m}^{-2}$. While agreeing well over the Atlantic Ocean, the two satellite products also show some surprisingly large discrepancies over the Sahara, the reasons for which are not entirely clear. The self-calibrating method used for SARAH probably leads to an underestimated cloud albedo in the region with persistent cloud cover, since the scenes with minimum number of counts are still contaminated with clouds. This leads to an overestimation of solar surface irradiance. On the other hand, the operational dataset suffers from temporal inhomogeneity as well as the inaccuracy of the cloud mask and the surface albedo that are needed as input and are derived with methods that do not rely on direct counts but on derived irradiances. Large differences between satellite products have also been noted in Knippertz et al. (2011, their Fig. S6) and Roehrig et al. (2013, their Fig. 10).

In contrast, ERA-I shows substantially lower values across the entire region with strong minima over mountainous regions and an area average of only $163 \mathrm{~W} \mathrm{~m}^{-2}$ (Fig. 4c). The strong gradients along the coast, where the land-sea breeze affects station observations, toward the Sahel, and around Lake Volta are not well resolved in ERA-I. Overall ERA-I appears to be slightly biased low relative to the station observations but generally agrees better than the satellite products. The mean over the eight YoTC models (Fig. 4d) is much flatter with fewer variations from the equatorial Atlantic across the stratus belt into the Sahel and less pronounced mountain peaks. The box average of
$186 \mathrm{~W} \mathrm{~m}^{-2}$ is substantially higher than ERA-I, more in accordance with the satellite products, which we suspect to be biased high. Nevertheless, given the large observational uncertainty, it is difficult to make any definite judgements. It should be kept in mind, however, that individual models show great deviations from the mean (see Figs. S6 and S7 in the SM), as already indicated by the cloud fields in Fig. 3. For some models (e.g., GISSE2, CNRM-AM, and MRI-AGCM3) the diurnal changes in radiation are broadly consistent with those in low-level cloudiness.

\section{b. Analysis of temperature and moisture tendencies}

In this section, tendencies of $\mathrm{RH}$ will be investigated to unveil reasons for the biases in cloudiness relative to ERA-I documented in section 4a. Exemplarily this will be done for MRI-AGCM3. This model was chosen, as it (a) shows some good qualitative agreement with ERA-I cloudiness (discernable diurnal cycle, vertical shift, overall cloud cover; see Figs. 3a-d) and wind profiles (Figs. 3e-h) and (b) agrees reasonably well with its CMIP5 counterpart (section 4a). Results for the other seven YoTC models will then be summarized relative to the MRI discussion.

\section{1) DETAILED COMPARISON BETWEEN ERA-I AND MRI-AGCM3}

To better understand discrepancies in cloudiness, Fig. 5 shows the diurnal cycle in the vertical profiles of $\mathrm{RH}$, again averaged over $5^{\circ}-10^{\circ} \mathrm{N}, 8^{\circ} \mathrm{W}-8^{\circ} \mathrm{E}$. For ERA-I (Fig. 5a), RH in the level of the nocturnal cloud maximum (i.e., $950 \mathrm{hPa}$ ) increases from $91 \%$ at $1800 \mathrm{UTC}$ to $95 \%$ at 0000 UTC and even $97 \%$ at 0600 UTC, whereas $\mathrm{RH}$ at $850 \mathrm{hPa}$ increases from $89 \%$ to $92 \%$. RH then drops to $90 \%$ at 1200 UTC at both levels, indicating that vertical mixing is already deep at midday. This behavior is consistent with the shift of the cloud deck to $850 \mathrm{hPa}$ (solid lines in Fig. 5a), as the critical RH value for cloud formation usually decreases with height in most subgrid cloud schemes (Sundqvist et al. 1989; Quaas 2012). RH already increases again at $950 \mathrm{hPa}$ between 1200 and 1800 UTC, suggesting a relatively early evening transition, as also visible in 2-m dewpoint observations from the region (Schuster et al. 2013, their Fig. 3d). The $850-\mathrm{hPa}$ value of $89 \%$ indicates moderate drying in the course of the afternoon, associated with the daytime warming of the PBL (not shown). This is accompanied by a significant reduction in cloud cover (solid lines in Fig. 5a). Overall, MRI-AGCM3 reproduces this behavior reasonably well (Fig. 5b). $\mathrm{RH}$ at $850 \mathrm{hPa}$ is only $0 \%-3 \%$ lower than ERA-I. Values at $950 \mathrm{hPa}$ deviate by $3 \%-4 \%$ during the night, consistent with the absence of a $950-\mathrm{hPa}$ cloud maximum, and by $6 \%$ at 1800 UTC, 


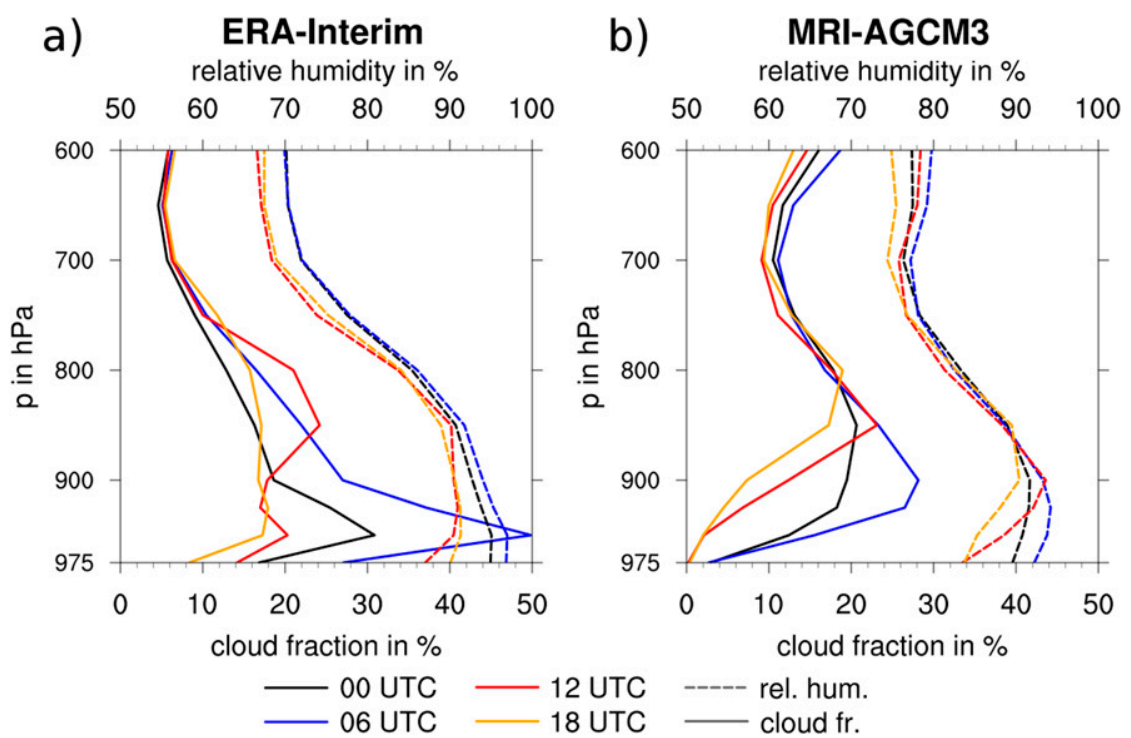

FIG. 5. Relation between RH (dashed lines, upper axes) and cloud fraction (solid lines, lower axes) for (a) ERA-I and (b) MRI-AGCM3. Plots show the diurnal cycle in lower-tropospheric profiles spatially averaged over the red box shown in Fig. 1 and temporally over JAS 1991-2010.

indicating a later evening transition. Additional factors leading to differences in low-cloud cover are the subgrid-cloud schemes employed (not investigated in detail here) and differences in the horizontal distribution of RH and clouds.

Therefore, Fig. 6 shows the diurnal cycles in low-level cloud and wind as horizontal distributions on a common $2.5^{\circ}$ raster. During the night, ERA-I shows an initial formation of clouds below $900 \mathrm{hPa}$ inland from the coast with some visible enhancement upstream of the Oshogbo Hills and the Jos Plateau (see Fig. 1) and a subsequent thickening and spreading of clouds farther inland (Figs. 6a,b). This is broadly consistent with highresolution model experiments by Schuster et al. (2013, their Fig. 5) and satellite observations by van der Linden et al. (2015, their Fig. 5). MRI-AGCM3 differs markedly with clouds being much more prevalent in the mountainous regions to the east and west of our study region as well as over the ocean, whereas the core of the study region shows much less cloud at 0000 UTC and a slow increase until 0600 UTC (Figs. 6e,f). Possibly, the higher resolution in ERA-I helps to realistically represent effects of the coast and hills. At 1200 UTC, cloud cover between 900 and $800 \mathrm{hPa}$ is typically between $20 \%$ and $30 \%$ over our study region in ERA-I and further decreases toward 1800 UTC (Figs. 6c,d). MRI-AGCM3 shows a generally similar behavior but with smaller absolute values (Figs. 6g,h).

To better understand the time evolution of the RH profiles, Fig. 7 shows an analysis of the contribution of various processes to $\mathrm{RH}$ tendencies as explained in section 2c. Unfortunately, ERA-I only provides tendencies over 3-h periods, while YoTC tendencies are instantaneous. During the more stable nighttime conditions, differences between midnight and accumulated values for 2100-0300 UTC are expected to be rather small, whereas for midday the more dynamic diurnal evolution may cause larger deviations. During the night, ERA-I shows a significant RH increase in the levels below $900 \mathrm{hPa}$, reaching a maximum of about $1 \%$ per hour near the surface (Fig. 7a). This value is broadly consistent with the increase in RH from $95 \%$ to $97 \%$ between 0000 and 0600 UTC (Fig. 5a). The main bulk of this is caused by cooling related to longwave radiation (light red line) and cold advection, which peaks at the jet level $950 \mathrm{hPa}$ (pink line). All other terms are close to zero or slightly negative, compensating a small fraction of the RH increase. Notably, vertical mixing (blue and turquoise lines) does not have a strong impact on RH in contrast to findings by Schuster et al. (2013) for smaller subregions. MRI-AGCM3 shows an overall similar pattern with RH increases below $900 \mathrm{hPa}$, mostly caused by radiative cooling and cold advection, but with the latter having a larger contribution (Fig. 7b). This must be related to a strong $T$ gradient, as the wind speed is lower in MRI-AGCM3 (see Fig. 3e). There is also a small positive contribution from cloud processes (gridscale and convection) in the lowest layers (light green), leading to cooling and moistening, probably through evaporating rain. Overall, the two models agree that $\mathrm{RH}$ increases due to moderate cooling, only partly compensated by a small decrease in $q$. 
ERA-Interim 00 UTC

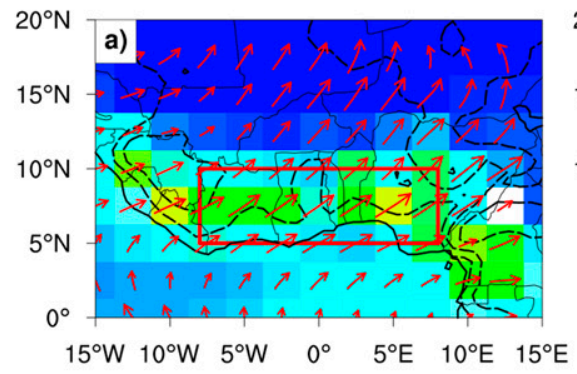

ERA-Interim 06 UTC

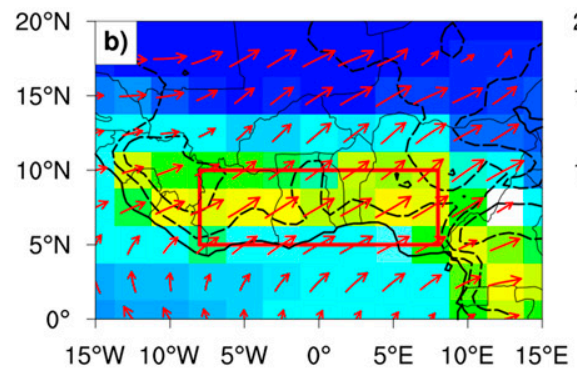

ERA-Interim 12 UTC

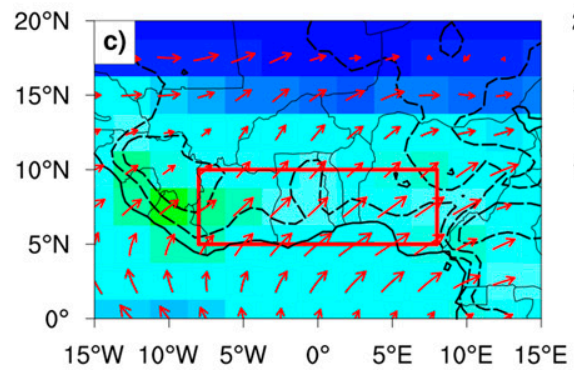

ERA-Interim 18 UTC

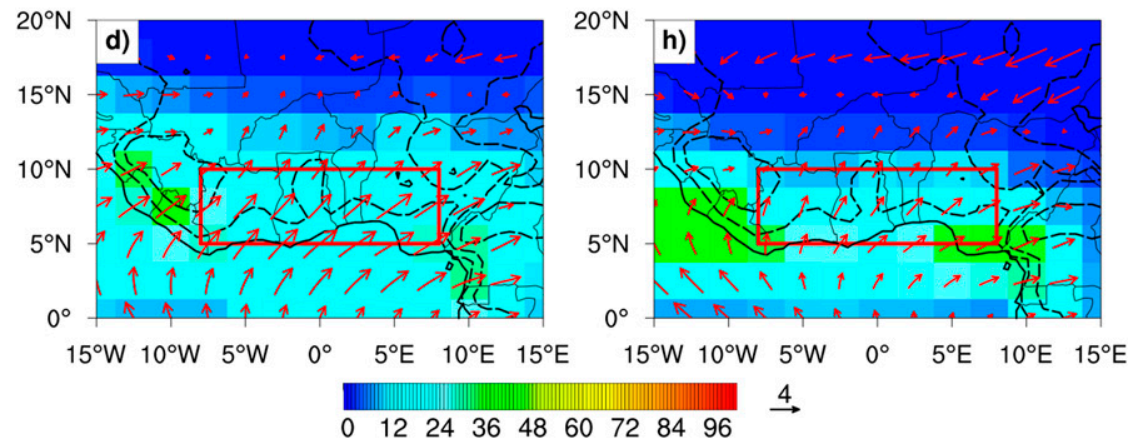

FIG. 6. Diurnal cycle of low clouds and winds for (left) ERA-I and (right) MRI-AGCM3. Plotted are the maximum cloud fraction (in \%) below $900 \mathrm{hPa}$ for 0000 and 0600 UTC, and between 800 and $900 \mathrm{hPa}$ for 1200 and $1800 \mathrm{UTC}$ as well as wind vectors at $900 \mathrm{hPa}$ (in m s${ }^{-1}$ according to the scale at the bottom). ERA-I data are interpolated to the standard $2.5^{\circ}$ grid for YoTC output and plotted as raster fill. ERA-I surface geopotential interpolated to each model's native horizontal grid is plotted as dashed isolines $(200,400$, and $800 \mathrm{~m})$ to provide an idea of the actual model orography. All data are temporally averaged over JAS 1991-2010. Red boxes are as in Fig. 1.

MRI-AGCM3 00 UTC
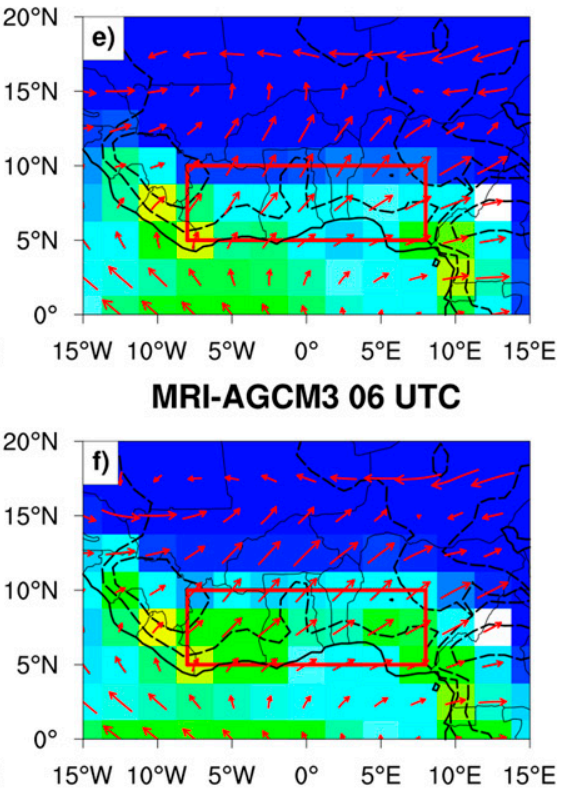

MRI-AGCM3 12 UTC

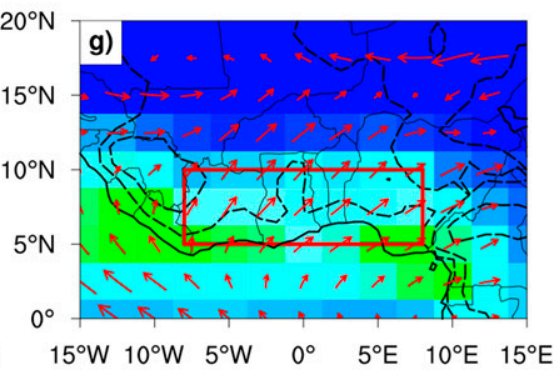

MRI-AGCM3 18 UTC 

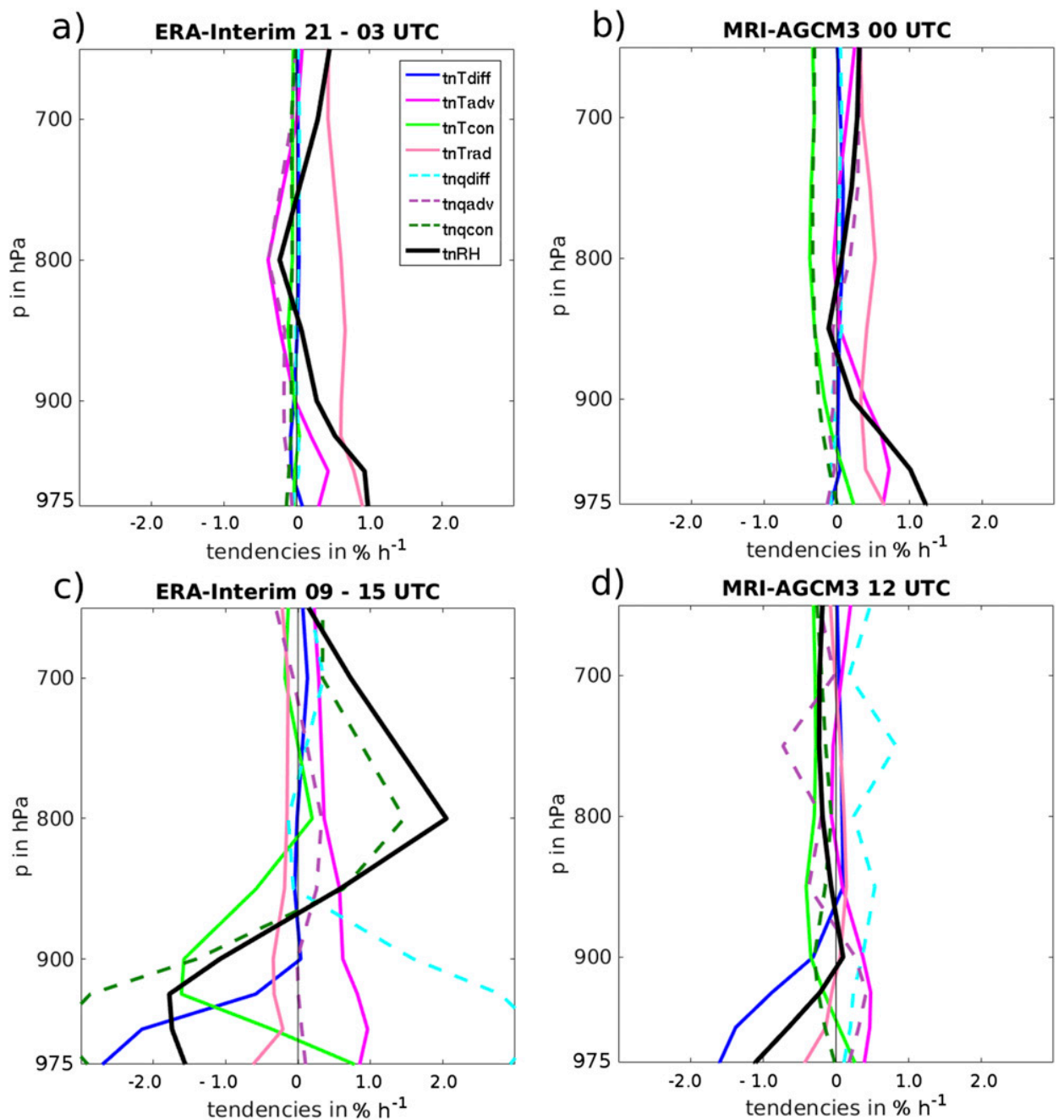

FIG. 7. Lower-tropospheric profiles of RH tendencies for (left) ERA-I and (right) MRI-AGCM3. Total tendencies are in black; contributions from individual processes (diffusion, convection, advection and radiation) related to changes in $T$ (solid) and $q$ (dashed) are in colors (see section 2a for details). All data are averaged spatially over the red box shown in Fig. 1 and temporally over JAS 1991-2010 (MRIAGCM3) and 2008-09 (ERA-I), respectively. Tendencies for ERA-I are 6-hourly accumulated for (top) 2100-0300 and (bottom) 0900-1500 UTC; MRI-AGCM3 data are instantaneous for (top) 0000 and (bottom) 1200 UTC.

At midday, differences between the two datasets are much more pronounced. ERA-I tendencies accumulated from 0900 to 1500 UTC are negative up to $875 \mathrm{hPa}$ with a maximum of $1.8 \%$ per hour at $925 \mathrm{hPa}$ followed by positive tendencies up to $2 \%$ until $650 \mathrm{hPa}$ (Fig. $7 \mathrm{c}$ ). These tendencies are consistent with the rapid upward shift of the cloud deck until 1200 UTC (Figs. 3b,c). In the lower layers the largest overall contributions are the positive tendencies related to vertical mixing of $q$ (light blue) that are almost exactly matched by negative tendencies from shallow convection (dark green), which then deposits this moisture in the 875-650-hPa layer. Contributions from $q$ advection (dashed purple line) are relatively small in the bottom layer, but contribute significantly to the moistening aloft. The decrease in $\mathrm{RH}$ at lower levels is mostly caused by radiative heating (light red) and warming by turbulent fluxes (blue), which overcompensate the effect of cold advection (pink). In addition, cloud processes heat the layer from 950 to $825 \mathrm{hPa}$ and cool the surface layer (light green), most likely through latent heat release and evaporation below cloud base. This suggests that the ECMWF model may even generate some light rain associated with these low clouds. Below $900 \mathrm{hPa}$, the decrease in $\mathrm{RH}$ is clearly dominated by the increase in $T$, while a net increase in $q$ only compensates a small fraction of this. 
Corresponding fields in MRI-AGCM3 show a fundamentally different structure (Fig. 7d). The layer of $\mathrm{RH}$ decrease is shallower and values are smaller, only reaching $1.3 \%$ per hour, while no significant increase aloft is found. The former is mostly related to radiative warming and turbulent transport of $T$, partly compensated by cold advection and evaporative cooling. The temperature tendency from convection is strikingly smaller than for ERA-I. Turbulent and convective transports of $q$ are also smaller, but there is again a leaning for temperature tendencies from convection and turbulence to compensate each other. In contrast to ERA-I, there is some moist advection at low levels counteracting the overall RH decrease. As for ERA-I, the decrease in RH is dominated by a $T$ increase partly compensated by an increase in $q$ but the magnitudes of terms are smaller. These results strongly suggest that the model substantially underrepresents the turbulent transport of $q$ from the soil into the PBL and then up to about $850 \mathrm{hPa}$ through shallow convection. It is not clear whether this is related to the soil or vegetation part of the land surface model (see Yukimoto et al. 2012). In any case, the coupling between the PBL and shallow convection parameterizations appears to differ substantially between the two models. A consequence of this is the reduced cloud cover in the afternoon hours (see Fig. 3c). Although the number of total vertical levels does not differ greatly (60 vs 48 ), those below $700 \mathrm{hPa}$ are considerably higher in ERA-I than in MRIAGCM3 (16 vs 10), which could explain at least part of the differences between the two models. In any case, the deviations appear considerably larger than what would be expected from impacts of the different time sampling (instantaneous vs accumulated).

The differences in low-cloud cover discussed above are clearly reflected in the fields of surface net solar radiation shown in Fig. 8. Between 0600 and 1200 UTC ERA-I and MRI-AGCM3 show overall good agreement and a clear local minimum in radiation over the stratus belt (identical averages over the study region of $294 \mathrm{~W} \mathrm{~m}^{-2}$; Figs. 8a,b), however with some underestimation of radiation over the tropical Atlantic Ocean in MRI-AGCM3. In the afternoon, ERA-I maintains a west-east-oriented minimum across SWA with the area average decreasing to $276 \mathrm{~W} \mathrm{~m}^{-2}$, particularly due to decreased solar radiation over southern Nigeria and Benin (Fig. 8c). This behavior disagrees with the tendency for afternoon cloud clearing documented in station observations (e.g., van der Linden et al. 2015) but is consistent with relatively early and abundant rainfalls in ERA-I, particularly over Nigeria and in association with the land-sea breeze (see Fig. S8 in the SM). This would explain the slight negative bias in
ERA-I discussed in the context of Fig. 4. In contrast, MRI-AGCM3 shows a marked increase in solar radiation during the afternoon, leading to a $65 \mathrm{~W} \mathrm{~m}^{-2}$ higher area average than ERA-I (Fig. 8d). This is most likely the reason for the later evening transition and lower $\mathrm{RH}$ at 1800 UTC discussed above (Fig. 5b).

In conclusion, these results reveal the following picture: At nighttime near-surface RH increases in both models due to radiative cooling and cold advection but only ERA-I produces a clear cloud maximum at $950 \mathrm{hPa}$. Possible reasons for this are slightly lower RH values in MRI-AGCM3 (Fig. 5), differences in subgrid cloud schemes (not investigated here), and a coarser resolution in MRI-AGCM3, making it harder to resolve coastal and orographic features (Fig. 6) shown to be responsible for cloud initiation (Schuster et al. 2013). During the afternoon, MRI-AGCM3 is too ineffective in transporting $q$ vertically to sustain a dense cloud deck at $850 \mathrm{hPa}$, leading to too much solar radiation, surface warming, low $\mathrm{RH}$, and a later evening transition. Possible reasons for this are differences in parameterizations and vertical resolution.

\section{2) Discussion OF OTHER YoTC MODELS}

The seven other YoTC models show many problems similar to those discussed for MRI-AGCM3 above but often with larger magnitudes. To summarize their overall behavior, Fig. 9 shows 950 - and 850 -hPa values of $\mathrm{RH}, \mathrm{RH}$ tendency, and cloud fraction for ERA-I and the YoTC models. Note that tendencies are 6-hourly for ERA-I and instantaneous for the YoTC models. Plots corresponding to Figs. 6-8 for individual models are provided in the SM.

GISS-E2 shows the closest agreement with MRIAGCM3 with almost identical $\mathrm{RH}$ values at $950 \mathrm{hPa}$ but drier values at $850 \mathrm{hPa}$ by $1 \%-2 \%$. RH tendencies (bars in Fig. 9) are also similar but cloud cover is slightly larger in GISS-E2 at $950 \mathrm{hPa}$ at 0600 UTC but smaller at $850 \mathrm{hPa}$ consistent with the somewhat lower RH values. Differences in nighttime clouds may again be related to differences in the $\mathrm{RH}$ distribution across the averaging box or to different critical $\mathrm{RH}$ in the subgrid cloud scheme. Looking at the profiles of $\mathrm{RH}$ tendencies (Fig. S5 in the SM) reveals similar behavior to MRIAGCM3 at nighttime, but more significant vertical $q$ transports during daytime. However, these do not lead to significant increases of $\mathrm{RH}$ around the $850-\mathrm{hPa}$ level as in ERA-I but deposit $q$ much higher at above $700 \mathrm{hPa}$. The resulting lack of daytime clouds leads to significantly overestimated surface solar radiation throughout the day of more than $100 \mathrm{~W} \mathrm{~m}^{-2}$ (Fig. S7 in the SM).

GEOS5 also has a relatively moist lower troposphere but with some significant biases in diurnal cycle and 
ERA-Interim 12 UTC

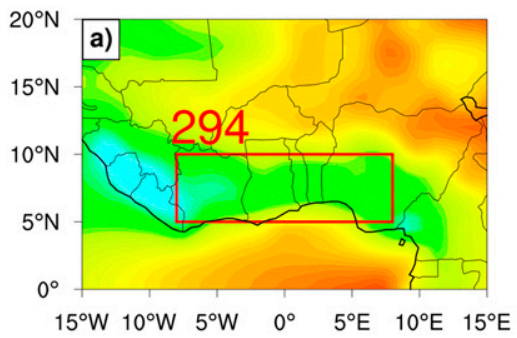

ERA-Interim 18 UTC

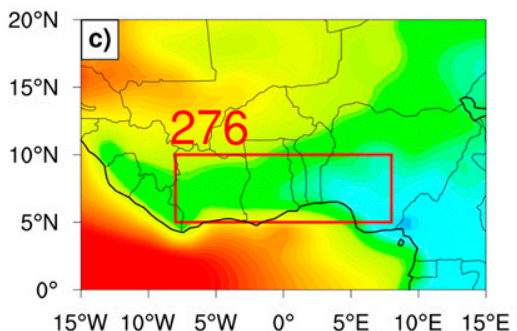

MRI-AGCM3 12 UTC

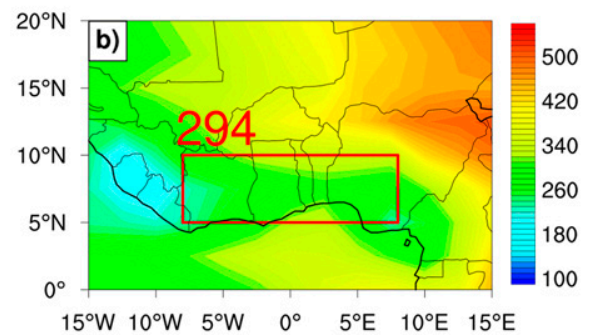

MRI-AGCM3 18 UTC

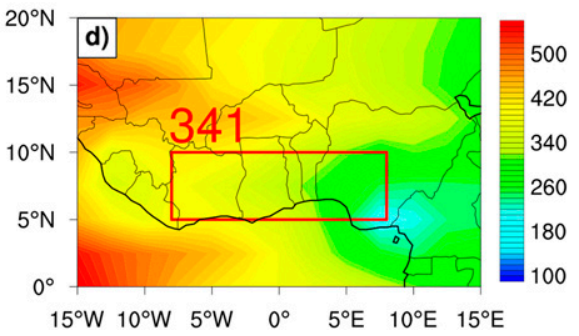

FIG. 8. Diurnal cycle of surface net shortwave flux in $\mathrm{W} \mathrm{m}^{-2}$ for (left) ERA-I and (right) MRIAGCM3, showing (top) 0600-1200 and (bottom) 1200-1800 UTC averages. All data are averaged over JAS 1991-2010. Red boxes are as in Fig. 1 with spatial averages given at the top.

cloud cover (Fig. 9). Although RH at both 950 and $850 \mathrm{hPa}$ at 0600 UTC is identical to MRI-AGCM3, cloud cover is much lower, again pointing to possible differences in $\mathrm{RH}$ distribution or in the subgrid cloud scheme. RH values at $950 \mathrm{hPa}(850 \mathrm{hPa})$ for all other times are lower (higher) than MRI-AGCM3, particularly at 1200 UTC, which hints at stronger vertical mixing during daytime. Nevertheless, somewhat

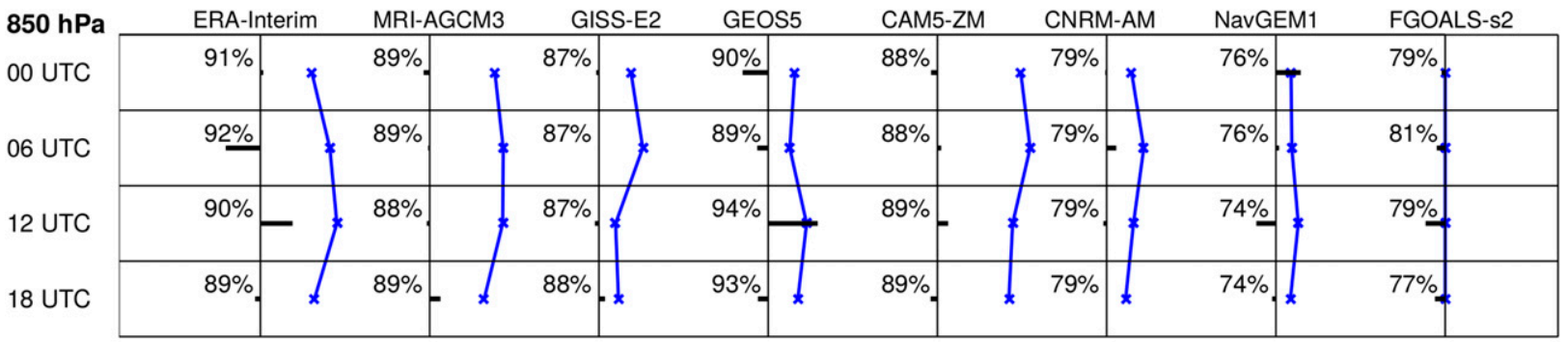

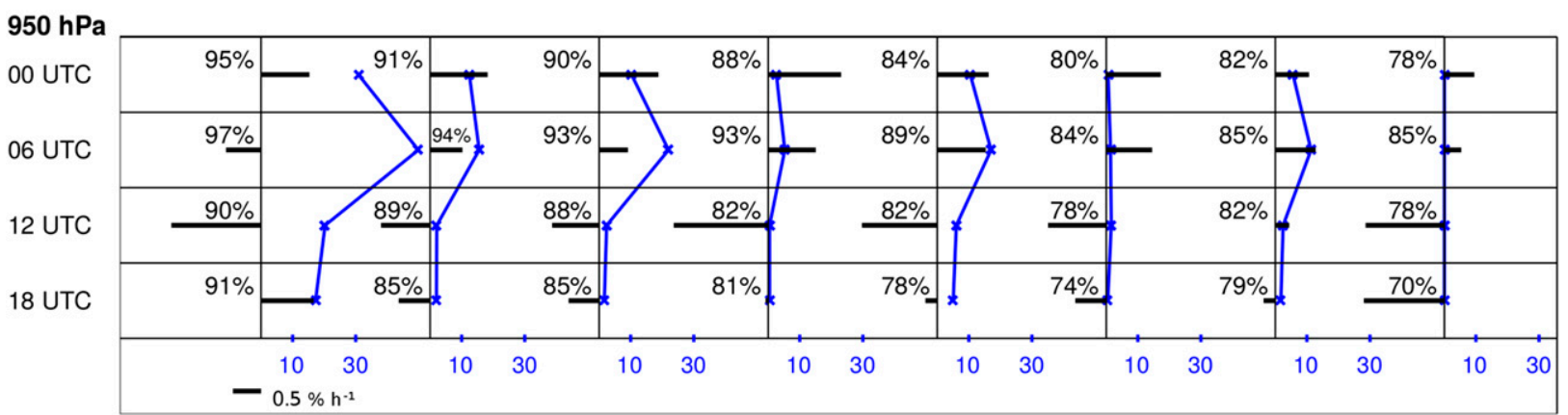

FIG. 9. Summary of diurnal cycle in RH (numbers), RH tendencies (bars), and cloud cover (blue lines) for YoTC models and ERA-I. Information is given for two vertical levels $(950$ and $850 \mathrm{hPa})$ and for four times of day $(0000,0600,1200$, and 1800 UTC). All data are spatially averaged over the red box shown in Fig. 1 and temporally over JAS 1991-2010. Note that RH tendencies are instantaneous for all YoTC models, while those from ERA-I are 6-hourly centered on the respective time (as in Fig. 7). No cloud data are provided for FGOALS-s2. 
surprisingly, cloud fraction is significantly smaller than in MRI-AGCM3 and ERA-I, which again points to a too conservative subgrid cloud scheme. This leads to positive surface net solar radiation biases in the afternoon (Fig. S7 in the SM), which support the deep daytime mixing. Daytime RH tendencies are dominated by turbulent fluxes of $T$ leading to marked warming below $900 \mathrm{hPa}$ and cooling between 900 and $800 \mathrm{hPa}$ (Fig. S5 in the SM). At the same time, turbulent $q$ fluxes are much larger and deeper than in MRI-AGCM3. Some of these effects, however, are compensated by convective warming and drying of the 800-900-hPa layer in contrast to ERA-I. These tendencies are somewhat at odds with the low cloud cover in this layer. Nighttime tendencies are again more consistent with ERA-I and the other YoTC models but the drier evening values make it more difficult to reach saturation near the surface by morning.

CAM5-ZM is characterized by a relatively stable cloud maximum at $850 \mathrm{hPa}$ with values around $25 \%$ (Figs. 3a-d). The closely related model CAM5 does not provide tendencies and is therefore not discussed here, but it is assumed that the overall model behavior will be similar. At $950 \mathrm{hPa}$ CAM5-ZM is significantly drier than MRI-AGCM3 by $4 \%-6 \%$ in RH throughout the day (Fig. 9). The fact that cloud cover is higher at this level suggests differences in the subgrid cloud scheme between the two models. At $850 \mathrm{hPa}$, the two models are much more similar in both $\mathrm{RH}$ values and cloud fraction, leading to similar patterns in surface solar radiation (Fig. S6 in the SM). Nighttime tendencies are again similar to the other models, while daytime tendencies agree in their overall characteristics with GEOS5 (Figs. S4 and S5 in the SM).

The three remaining models, CNRM-AM, NavGEM1, and FGOALS-s2, are all characterized by significantly too low RH at both levels at all times (Fig. 9). For CNRM-AM and NavGEM1 typical deviations in RH from ERA-I are on the order of $10 \%$ but reach values as high as $17 \%$ for NavGEM1 at $850 \mathrm{hPa}$ at $1200 \mathrm{UTC}$. FGOALS-s2 even reaches $22 \% \mathrm{RH}$ bias at $950 \mathrm{hPa}$ at 1800 UTC. Consequently, it is no surprise that these models show too low cloud cover and too high surface solar radiation (note that cloud information for FGOALS-s2 appears to be erroneous as discussed in section 4a). With respect to nighttime tendencies, CNRM-AM shows patterns similar to most other YoTC models, but in NavGEM1 cold advection is relatively weak and radiative cooling stronger than in any other model (see SM). This is consistent with the low RH allowing for more energy loss to space during the night. CNRM-AM has one of the strongest LLJs of all models (Fig. 3f), leading to large nighttime $T$ tendencies from turbulent diffusion, but interestingly advective tendencies are not particularly large. FGOALS-s2 shows radiative cooling similar to other models, but, unlike most other models, also remarkable cooling (i.e., $\mathrm{RH}$ increase) related to turbulent mixing under the nighttime jet, which is stronger than in any other model (Figs. 3e,f). During daytime the low levels in FGOALSs2 and NavGEM1 are dominated by RH decreases, mostly from warming by diffusion and $q$ removal by convection. CNRM-AM is similar at 1200 UTC but has positive RH tendencies at $800 \mathrm{hPa}$ at 1800 UTC supported by unrealistic moist advection at this level (not shown).

\section{3) SYNTHESIS}

The detailed analysis of the eight YoTC models has shown a range of different behaviors, errors, and biases that allows us to develop some hypotheses on possible reasons. To do this in a systematic way, Fig. 10 shows an evaluation of many of the parameters discussed in this paper. The coloring in this figure is based on deviations from ERA-I measured in standard deviations (see figure caption for more details).

Not surprisingly, the overall model performance depends to some degree on resolution (rows 1 and 2 in Fig. 10). Two models with relatively high horizontal and vertical resolution, MRI-AGCM3 and GEOS5, have the lowest numbers of large deviations from ERA-I (dark red and blue in Fig. 10) while the coarsest model, FGOALS-s2, has a high number (and not all tested parameters are available). On the other hand, finer resolution alone is not sufficient, as indicated by the moderate performance of NavGEM1 (which has even higher horizontal resolution than ERA-I). Daytime vertical transport of heat and moisture by surface fluxes, turbulent diffusion, and shallow and deep convection (third row in Fig. 10), as qualitatively diagnosed from the RH tendencies (Fig. 7; see also Figs. S4 and S5 in the $\mathrm{SM}$ ), tends to be weaker than ERA-I in all models with GEOS5 performing best. Although this is the model with the highest number of vertical levels, there is no systematic correlation, indicating that parameterizations probably play a more important role. It is, of course, also possible that the placing of model levels can play some role, as for example MRI-AGCM3's total number of vertical levels is not much smaller than ERAI (48 vs 60), but levels below $700 \mathrm{hPa}$ are considerably less (10 vs 16).

With regard to RH at $950 \mathrm{hPa}$ (rows 4 and 5 in Fig. 10), all models show too low values and all but three a too large diurnal range. There are indications for an anticorrelation between these two parameters. For the majority of models, the negative bias in $\mathrm{RH}$ is associated with too little cover of low clouds (both average and 

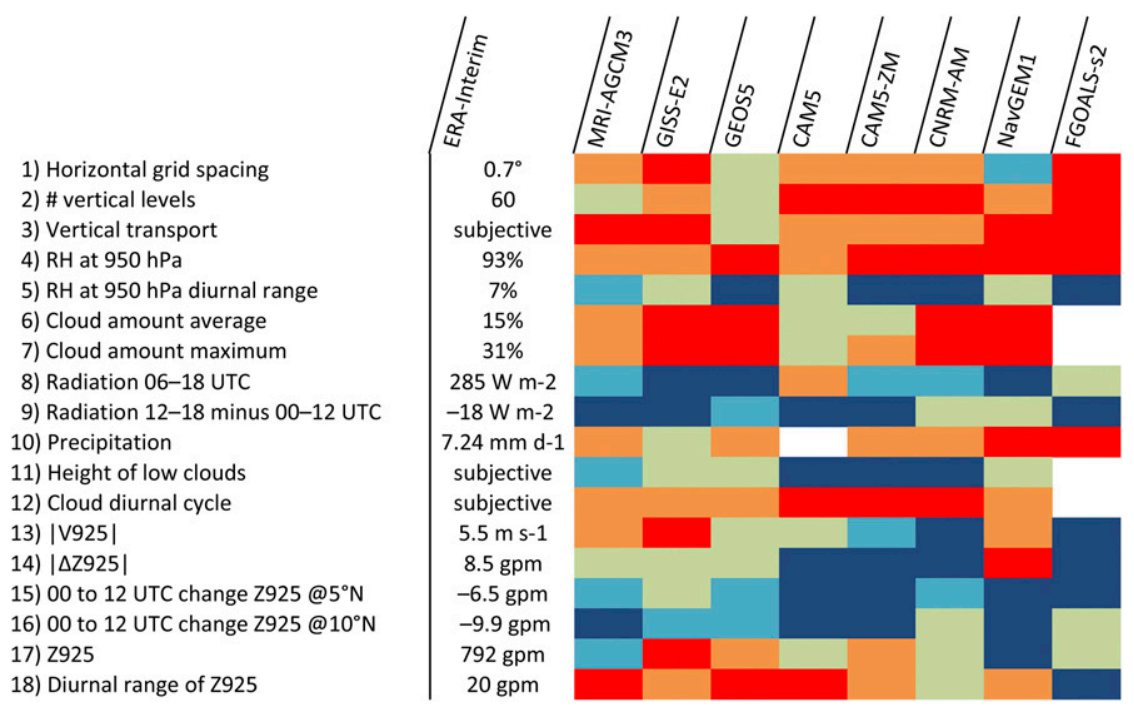

FIG. 10. Systematic evaluation of YoTC models relative to ERA-I. Apart from model resolution (rows 1 and 2) and the geopotential height changes at $5^{\circ}$ and $10^{\circ} \mathrm{N}$ as well as their differences (rows 14-16), all parameters are spatially averaged over the red box shown in Fig. 1 and temporally over JAS 1991-2010. Parameters are either computed from model data or evaluated subjectively (see ERA-I value given in the second column). For computed parameters, the colors used are based on differences from ERA-I as measured in standard deviations $(\sigma)$ computed from all models and ERA-I. Within half $\sigma$ (green), between half and one $\sigma$ (light red for lower, light blue for higher values), greater than one $\sigma$ (dark red for lower, dark blue for higher values), and no data (white). The cloud amounts averages and maxima in rows 6 and 7 refer to levels below $600 \mathrm{hPa}$. For precipitation and the changes in geopotential in rows 15 and 16,1 and $2 \sigma$ are used instead of 0.5 and $1 \sigma$.

maximum, rows 6 and 7 in Fig. 10), which in turn leads to too much incoming solar radiation (row 8 ) and a too large change from the first to the second half of the day (row 9), indicating too sunny afternoons. Greater dryness can also enhance nighttime radiative cooling, further increasing the diurnal amplitude. This demonstrates a physical link between absolute RH and its diurnal range via cloud cover and radiative heating, which may even offer a mechanism for feedback. A notable exception to the pattern described above is CAM5, which has slightly too low RH, but satisfactory cloud amount and RH diurnal range, while radiation is even lower than ERA-I but with a larger diurnal change. It is also stressed here that the close correlation between lowcloud amount and radiation indicates that the influence of mid- and higher-level clouds (and possibly aerosols, which are prescribed in the models) is relatively small. However, even for similar RH values, the exact amount of clouds the models produce varies considerably, which points to differences in the subgrid cloud schemes. There is no clear relationship between resolution and cloud amount, indicating that insufficiently resolved topographic features that act to enhance lowlevel cloudiness are unlikely a dominating factor. This is also evident from the CMIP5 models.
The overall dry bias in most models is also associated with a negative precipitation bias (row 10 in Fig. 10; see also Fig. S8 in SM), which in turn shows some correlation to the reduced vertical transport. Cloud elevation is similar or too high relative to ERA-I (row 11). Diurnal changes in cloud amount and height (row 12) are too small in all models, but particularly in those with too elevated clouds that are less affected by the underlying surface. There is a mild correlation between this parameter and the number of vertical levels. There is not a very clear correspondence between the diurnal changes in clouds with those in $\mathrm{RH}$ and radiation.

The last block of parameters (rows 13-18 in Fig. 10) is related to geopotential and wind. Mean winds at $925 \mathrm{hPa}$ show a wide spread with three models each under- and overestimating and two showing satisfactory agreement with ERA-I. There is no clear correlation between wind and cloud parameters, most likely due to compensating effects of $T$ and $q$ advection as well as turbulent mixing at night. Correlations between wind and north-south geopotential differences at $925 \mathrm{hPa}$ are also not as large as expected. This is to some extent related to substantial differences in wind direction, as clearly demonstrated by NavGEM1, where the monsoon wind is very unrealistic (see Figs. S2 and S3 in the SM). The 0000-1200 UTC 
decrease in geopotential height at both $5^{\circ}$ and $10^{\circ} \mathrm{N}$ are underestimated in most models, possibly associated with less convective heating than in ERA-I [see section 4a(1)]. For some models biases compensate each other to give an overall satisfactory gradient. Consequently the diurnal range is smaller than in ERA-I in most models, the exception being FGOALS-s2, which simulates a very steep drop in geopotential height in the afternoon (not shown). The absolute values of 925 -hPa geopotential are quite variable between models but do not show any systematic relationship to any of the other parameters.

\section{Conclusions}

Low-level clouds are ubiquitous over SWA during the summer monsoon from July-September. They influence incoming solar radiation and thus the surface energy budget with potential impacts on convective initiation and precipitation. They form during the night underneath the core of the southwesterly LLJ spreading from the coast farther inland and then lift, break open, and dissolve in the course of the day. Here we evaluated the representation of these low-level clouds in global climate models contained in the CMIP5 (18 models, 1979-2008) and YoTC (8 models, some also in CMIP5, 1991-2010) datasets using ERA-I and satellite- and ground-based observations, thereby providing an update and an extension to the work of Knippertz et al. (2011) for CMIP3. In particular the YoTC dataset with its four times daily output and tendencies from parameterized processes allows a much more in-depth analysis of biases and their reasons.

As in CMIP3, the models show a wide spread in their representation of low-level clouds over SWA with an overall tendency for an underestimation in cover and an overestimation of cloud height, leading to an overestimation of downwelling solar radiation at the surface on average. The majority of models also overestimates the LLJ in agreement with Knippertz et al. (2011). For some models, this appears to be at least partly related to a too large north-south geopotential difference across the region. However, the relationship between geopotential and wind is not linear when comparing different models. The diurnal cycle in geopotential height is smaller than in ERA-I, possibly due to differences in convective heating (see Marsham et al. 2013), while differences in solar heating appear to be less important. In addition, the YoTC models show a tendency for too weak diurnal cycles in cloud behavior.

A number of possible reasons why models struggle to realistically represent the low-level clouds have been identified in this paper. Previous work has postulated that nighttime turbulent mixing under the LLJ plays a role for their formation (e.g., Schuster et al. 2013). This effect, however, appears to be small for ERA-I and the YoTC models, apart from those that greatly overestimate the jet. In addition, the jet is connected to cold and dry advection, whose effects on clouds can compensate each other to some extent, leaving an overall unclear wind-cloud relationship in the models. Consistent with their negative cloud biases, most YoTC models tend to have too low RH at low levels when compared to ERA-I. Tendencies in RH computed for the YoTC models are largely consistent with ERA-I during night with RH increases mostly due to cold advection and longwave radiative cooling with very dry models overestimating the latter. Daytime tendencies reveal significant problems with the vertical redistribution of heat and moisture. ERA-I shows much larger vertical transports through turbulent diffusion and shallow convection, leading to a large diurnal shift in the height of low-level clouds. As there is no clear dependence of this behavior on vertical resolution, differences in the interactions between different parameterizations appear a more likely cause. As a result of the underestimation of clouds, models are too dry and too sunny in the afternoon and show a delayed evening transition. It would be plausible that the enhancement of clouds by coastal and orographic features is underrepresented in coarse-resolution models, but no clear dependence on horizontal grid spacing could be identified. Interestingly, even for similar RH values, cloud cover differs between models, pointing to differences in subgrid cloud schemes.

The results presented here can help model developers to explore effects of parameterized processes on $T$ and $q$ distributions. It will be interesting to investigate how errors in cloudiness feed back on thermodynamic conditions. It is conceivable that a lack of clouds and the associated surface heating and low RH lead to a slow drying of the soil. At the same time, there appears to be a correlation of low-level RH and precipitation, which could further deteriorate the drying trend. Less clouds and precipitation implies less latent heating but also more solar heating, with an unknown net effect on winds and advection. The balance of these different processes and the involved time scales, as well as their impact on the regional WAM circulation, are unclear. Zheng and Eltahir (1998), for example, point to a large sensitivity of the meridional overturning monsoon circulation to surface perturbations in SWA, but not in the Sahel, thus suggesting some larger-scale effects of the misrepresentation of the lower-tropospheric water and energy budgets in this area.

Targeted sensitivity experiments are needed to carefully disentangle these feedbacks. This also holds for the cloud-wind coupling, which appears to be less important 
than previously thought from the results presented here, but this may also be a problem of insufficient resolution. Last, it is urgently needed to improve the availability of good observational data from this region to better constrain analysis and evaluate models, as some possible deficiencies of ERA-I have been identified here. The Dynamics-Aerosol-Chemistry-Cloud Interactions over West Africa (DACCIWA) project organized a major international field campaign in SWA (Knippertz et al. 2015) in June-July 2016. It is hoped that observational data from this activity will further advance our understanding of low-level clouds and their representation in models.

Acknowledgments. The research leading to these results has received funding from the European Union 7th Framework Programme (FP7/2007-2013) under Grant Agreement 603502 (EU project DACCIWA: DynamicsAerosol-Chemistry-Cloud Interactions in West Africa). The GASS-YoTC Vertical Structure and Physical Processes Multi-model Experiment was supported by the World Climate Research Program and World Weather Research Program and organized by the GEWEX Global Atmospheric System Studies (GASS) subproject and the YoTC/WGNE Madden-Julian Oscillation Task Force. Data from EUMETSATs Satellite Application Facility on Climate Monitoring (CM SAF) were used. Radiation measurements at Cotonou and Parakou were carried out by the IMPETUS project funded by the BMBF project IMPETUS (BMBF Grant 01LW06001A, North Rhine-Westphalia Grant 313-21200200). We particularly thank Orou Goura Doussi and Michael Christoph for their maintenance and data retrieval commitment for the Parakou station. We also wish to thank the World Radiation Monitoring Center for radiation data from Ilorin and Dr. Arturo Sanchez-Lorenzo from the Pyrenean Institute of Ecology for the provision of the radiance data from the Ghanaian stations as well as Abdourahamane Konaré, Adama Diawara, and Fidèle Yoroba for providing the radiation data from the Lamto Geophysical Observatory in Ivory Coast. The authors thank three anonymous reviewers for their excellent comments that substantially improved this paper and Roderick van der Linden for preparing CALIPSO cloud profiles that helped in the discussion of the results.

\section{REFERENCES}

Abdou, K., D. J. Parker, B. Brooks, N. Kalthoff, and T. Lebel, 2010: The diurnal cycle of lower boundary-layer wind in the West African monsoon. Quart. J. Roy. Meteor. Soc., 136 (S1), 66-76, doi:10.1002/qj.536.

Agustí-Panareda, A., and Coauthors, 2010: The ECMWF reanalysis for the AMMA observational campaign. Quart. J. Roy. Meteor. Soc., 136, 1457-1472, doi:10.1002/qj.662.
Bao, Q., and Coauthors, 2013: The Flexible Global OceanAtmosphere-Land System model version: FGOALS-s2. Adv. Atmos. Sci., 30, 561-576, doi:10.1007/s00376-012-2113-9.

Benson, C., and E. J. Clay, 1998: The impact of drought on subSaharan economies. World Bank Tech. Paper 401, 80 pp.

Biasutti, M., I. Held, A. Sobel, and A. Giannini, 2008: SST forcings and Sahel rainfall variability in simulations of the twentieth and twenty-first centuries. J. Climate, 21, 3471-3486, doi:10.1175/2007JCLI1896.1.

Birch, C. E., D. Parker, J. Marsham, D. Copsey, and L. GarciaCarreras, 2014: A seamless assessment of the role of convection in the water cycle of the West African monsoon. J. Geophys. Res. Atmos., 119, 2890-2912, doi:10.1002/2013JD020887.

Brandt, P., and Coauthors, 2011: Equatorial upper-ocean dynamics and their interaction with the West African monsoon. Atmos. Sci. Lett., 12, 24-30, doi:10.1002/asl.287.

Christensen, J. H., and Coauthors, 2013: Climate phenomena and their relevance for future regional climate change. Climate Change 2013: The Physical Science Basis, T. F. Stocker et al., Eds., Cambridge University Press, 1217-1308.

Couvreux, F., F. Guichard, A. Gounou, D. Bouniol, P. Peyrillé, and M. Köhler, 2014: Modelling of the thermodynamical diurnal cycle in the lower atmosphere: A joint evaluation of four contrasted regimes in the tropics over land. Bound.-Layer Meteor., 150, 185-214, doi:10.1007/s10546-013-9862-6.

Dee, D., and Coauthors, 2011: The ERA-Interim reanalysis: Configuration and performance of the data assimilation system. Quart. J. Roy. Meteor. Soc., 137, 553-597, doi:10.1002/ qj. 828.

Donner, L. J., and Coauthors, 2011: The dynamical core, physical parameterizations, and basic simulation characteristics of the atmospheric component AM3 of the GFDL global coupled model CM3. J. Climate, 24, 3484-3519, doi:10.1175/ 2011JCLI3955.1.

Dufresne, J.-L., and Coauthors, 2012: Climate change projections using the IPSL-CM5 Earth system model: From CMIP3 to CMIP5. Climate Dyn., 40, 2123-2165, doi:10.1007/ s00382-012-1636-1.

Eltahir, E. A. B., and C. Gong, 1996: Dynamics of wet and dry years in West Africa. J. Climate, 9, 1030-1042, doi:10.1175/ 1520-0442(1996)009<1030:DOWADY > 2.0.CO;2.

Garcia-Carreras, L., and Coauthors, 2013: The impact of convective cold pool outflows on model biases in the Sahara. Geophys. Res. Lett., 40, 1647-1652, doi:10.1002/grl.50239.

Gent, P. R., and Coauthors, 2011: The Community Climate System Model version 4. J. Climate, 24, 4973-4991, doi:10.1175/ 2011JCLI4083.1.

Gounou, A., F. Guichard, and F. Couvreux, 2012: Observations of diurnal cycles over a West African meridional transect: Premonsoon and full-monsoon seasons. Bound.-Layer Meteor., 144, 329-357, doi:10.1007/s10546-012-9723-8.

Hall, N. M., and P. Peyrillé, 2006: Dynamics of the West African monsoon. J. Phys. IV, 139, 81-99, doi:10.1051/jp4:2006139007.

Hazeleger, W., and Coauthors, 2012: EC-Earth V2.2: Description and validation of a new seamless Earth system prediction model. Climate Dyn., 39, 2611-2629, doi:10.1007/ s00382-011-1228-5.

Hogan, T. F., and Coauthors, 2014: The Navy Global Environmental Model. Oceanography, 27, 116-125, doi:10.5670/ oceanog.2014.73.

Hourdin, F., and Coauthors, 2010: AMMA-Model Intercomparison Project. Bull. Amer. Meteor. Soc., 91, 95-104, doi:10.1175/ 2009BAMS2791.1. 
Iversen, T., and Coauthors, 2013: The Norwegian Earth System Model, NorESM1-M-Part 2: Climate response and scenario projections. Geosci. Model Dev., 6, 389-415, doi:10.5194/ gmd-6-389-2013.

Ji, D., and Coauthors, 2014: Description and basic evaluation of Beijing Normal University Earth System Model (BNU-ESM) version 1. Geosci. Model Dev., 7, 2039-2064, doi:10.5194/ gmd-7-2039-2014.

Jiang, X., and Coauthors, 2015: Vertical structure and physical processes of the Madden-Julian oscillation: Exploring key model physics in climate simulations. J. Geophys. Res. Atmos., 120, 4718-4748, doi:10.1002/2014JD022375.

Kim, D., A. H. Sobel, A. D. D. Genio, Y. Chen, S. J. Camargo, M.-S. Yao, M. Kelley, and L. Nazarenko, 2012: The tropical subseasonal variability simulated in the NASA GISS general circulation model. J. Climate, 25, 4641-4659, doi:10.1175/ JCLI-D-11-00447.1.

Knippertz, P., A. H. Fink, R. Schuster, J. Trentmann, J. M. Schrage, and C. Yorke, 2011: Ultra-low clouds over the southern West African monsoon region. Geophys. Res. Lett., 38, L21808, doi:10.1029/2011GL049278.

—_ and Coauthors, 2015: The DACCIWA project: DynamicsAerosol-Chemistry-Cloud Interactions in West Africa. Bull. Amer. Meteor. Soc., 96, 1451-1460, doi:10.1175/ BAMS-D-14-00108.1.

Li, L., and Coauthors, 2012: The Flexible Global OceanAtmosphere-Land System Model: Grid-point version 2: FGOALS-g2. Adv. Atmos. Sci., 30, 543-560, doi:10.1007/ s00376-012-2140-6.

Lothon, M., F. Said, F. Lohou, and B. Campistron, 2008: Observation of the diurnal cycle in the low troposphere of West Africa. Mon. Wea. Rev., 136, 3477-3500, doi:10.1175/2008MWR2427.1.

Marsham, J. H., N. S. Dixon, L. Garcia-Carreras, G. Lister, D. J. Parker, P. Knippertz, and C. E. Birch, 2013: The role of moist convection in the West African monsoon system: Insights from continental-scale convection-permitting simulations. Geophys. Res. Lett., 40, 1843-1849, doi:10.1002/grl.50347.

Martin, E. R., and C. Thorncroft, 2015: Representation of African easterly waves in CMIP5 models. J. Climate, 28, 7702-7715, doi:10.1175/JCLI-D-15-0145.1.

Meynadier, R., O. Bock, S. Gervois, F. Guichard, J.-L. Redelsperger, A. Agustí-Panareda, and A. Beljaars, 2010: West African monsoon water cycle: 2. Assessment of numerical weather prediction water budgets. J. Geophys. Res., 115, D19107, doi:10.1029/2010JD013919.

Milton, S. F., G. Greed, M. E. Brooks, J. Haywood, B. Johnson, R. P. Allan, A. Slingo, and W. M. F. Grey, 2008: Modeled and observed atmospheric radiation balance during the West African dry season: Role of mineral dust, biomass burning aerosol, and surface albedo. J. Geophys. Res., 113, D00C02, doi:10.1029/2007JD009741.

Molod, A., L. Takacs, L. M. Suarez, J. Bacmeister, I.-S. Song, and A. Eichmann, 2012: The GEOS-5 atmospheric general circulation model: Mean climate and development from MERRA to Fortuna. NASA Tech. Rep. NASA TM-2012-104606, Vol. 28, 117 pp.

Mueller, R., C. Matsoukas, A. Gratzki, H. Behr, and R. Hollmann, 2009: The CM-SAF operational scheme for the satellite based retrieval of solar surface irradiance-A LUT based eigenvector hybrid approach. Remote Sens. Environ., 113, 10121024, doi:10.1016/j.rse.2009.01.012.

Müller, R., U. Pfeifroth, C. Träger-Chatterjee, R. Cremer, J. Trentmann, and R. Hollmann, 2015: Surface Solar Radiation
Data Set-Heliosat (SARAH)-Edition 1. Satellite Application Facility on Climate Monitoring, accessed 3 September 2016, doi:10.5676/EUM_SAF_CM/SARAH/V001.

Nam, C., S. Bony, J.-L. Dufresne, and H. Chepfer, 2012: The 'too few, too bright' tropical low-cloud problem in CMIP5 models. Geophys. Res. Lett., 39, L21801, doi:10.1029/2012GL053421.

Neale, R. B., and Coauthors, 2012: Description of the NCAR Community Atmosphere Model: CAM 5.0. NCAR Tech. Rep. NCAR/TN-486+STR, 274 pp. [Available online at www.cesm. ucar.edu/models/cesm1.0/cam/docs/description/cam5_desc.pdf.]

Nicholson, S. E., 2001: Climatic and environmental change in Africa during the last two centuries. Climate Res., 17, 123-144, doi:10.3354/cr017123.

Parker, D., and Coauthors, 2005: The diurnal cycle of the West African monsoon circulation. Quart. J. Roy. Meteor. Soc., 131, 2839-2860, doi:10.1256/qj.04.52.

Paxian, A., and Coauthors, 2016: Bias reduction in decadal predictions of West African monsoon rainfall using regional climate models. J. Geophys. Res. Atmos., 121, 1715-1735, doi:10.1002/2015JD024143.

Posselt, R., R. W. Mueller, R. Stöckli, and J. Trentmann, 2012: Remote sensing of solar surface radiation for climate monitoring the CM-SAF retrieval in international comparison. $R e$ mote Sens. Environ., 118, 186-198, doi:10.1016/j.rse.2011.11.016.

Quaas, J., 2012: Evaluating the "critical relative humidity" as a measure of subgrid-scale variability of humidity in general circulation model cloud cover parameterizations using satellite data. J. Geophys. Res., 117, D09208, doi:10.1029/2012JD017495.

Reynolds, R. W., N. A. Rayner, T. M. Smith, D. C. Stokes, and W. Wang, 2002: An improved in situ and satellite SST analysis for climate. J. Climate, 15, 1609-1625, doi:10.1175/ 1520-0442(2002)015<1609:AIISAS > 2.0.CO;2.

Roberts, A., J. H. Marsham, and P. Knippertz, 2015: Disagreements in low-level moisture between (re)analyses over summertime West Africa. Mon. Wea. Rev., 143, 1193-1211, doi:10.1175/MWR-D-14-00218.1.

Roehrig, R., D. Bouniol, F. Guichard, F. Hourdin, and J.-L. Redelsperger, 2013: The present and future of the West African monsoon: A process-oriented assessment of CMIP5 simulations along the AMMA transect. J. Climate, 26, 64716505, doi:10.1175/JCLI-D-12-00505.1.

Rotstayn, L. D., S. J. Jeffrey, M. A. Collier, S. M. Dravitzki, A. C. Hirst, J. I. Syktus, and K. K. Wong, 2012: Aerosol- and greenhouse gas-induced changes in summer rainfall and circulation in the Australasian region: A study using single-forcing climate simulations. Atmos. Chem. Phys., 12, 6377-6404, doi:10.5194/ acp-12-6377-2012.

Schmidt, G. A., and Coauthors, 2014: Configuration and assessment of the GISS ModelE2 contributions to the CMIP5 archive. J. $A d v$. Model. Earth Syst., 6, 141-184, doi:10.1002/2013MS000265.

Schrage, J. M., and A. H. Fink, 2012: Nocturnal continental lowlevel stratus over tropical West Africa: Observations and possible mechanisms controlling its onset. Mon. Wea. Rev., 140, 1794-1809, doi:10.1175/MWR-D-11-00172.1.

_ S. Augustyn, and A. Fink, 2007: Nocturnal stratiform cloudiness during the West African monsoon. Meteor. Atmos. Phys., 95, 73-86, doi:10.1007/s00703-006-0194-7.

Schuster, R., A. H. Fink, and P. Knippertz, 2013: Formation and maintenance of nocturnal low-level stratus over the southern West African monsoon region during AMMA 2006. J. Atmos. Sci., 70, 2337-2355, doi:10.1175/JAS-D-12-0241.1.

Scoccimarro, E., and Coauthors, 2011: Effects of tropical cyclones on ocean heat transport in a high resolution coupled general 
circulation model. J. Climate, 24, 4368-4384, doi:10.1175/ 2011JCLI4104.1.

Song, X., and G. J. Zhang, 2011: Microphysics parameterization for convective clouds in a global climate model: Description and single-column model tests. J. Geophys. Res., 116, D02201, doi:10.1029/2010JD014833.

Stevens, B., and Coauthors, 2012: The atmospheric component of the MPI-M Earth system model: ECHAM6. J. Adv. Model. Earth Syst., 5, 146-172, doi:10.1002/jame.20015.

Sundqvist, H., E. Berge, and J. E. Kristjánsson, 1989: Condensation and cloud parameterization studies with a mesoscale numerica weather prediction model. Mon. Wea. Rev., 117, 1641-1657, doi:10.1175/1520-0493(1989)117<1641:CACPSW>2.0.CO;2.

Taylor, K. E., R. J. Stouffer, and G. A. Meehl, 2012: An overview of CMIP5 and the experiment design. Bull. Amer. Meteor. Soc., 93, 485-498, doi:10.1175/BAMS-D-11-00094.1.

van der Linden, R., A. H. Fink, and R. Redl, 2015: Satellite-based climatology of low-level continental clouds in southern West Africa during the summer monsoon season. J. Geophys. Res. Atmos., 120, 1186-1201, doi:10.1002/2014JD022614.

Vellinga, M., A. Arribas, and R. Graham, 2013: Seasonal forecasts for regional onset of the West African monsoon. Climate Dyn., 40, 3047-3070, doi:10.1007/s00382-012-1520-z.

Voldoire, A., and Coauthors, 2013: The CNRM-CM5.1 global climate model: Description and basic evaluation. Climate Dyn., 40, 2091-2121, doi:10.1007/s00382-011-1259-y.

Volodin, E. M., N. A. Dianskii, and A. V. Gusev, 2010: Simulating present-day climate with the INMCM4.0 coupled model of the atmospheric and oceanic general circulations. Izv. Atmos. Ocean. Phys., 46, 414-431, doi:10.1134/S000143381004002X.

Waliser, D. E., and Coauthors, 2012: The "year" of tropical convection (May 2008-April 2010): Climate variability and weather highlights. Bull. Amer. Meteor. Soc., 93, 1189-1218, doi:10.1175/2011BAMS3095.1.

Watanabe, M., and Coauthors, 2010: Improved climate simulation by MIROC5: Mean states, variability, and climate sensitivity. J. Climate, 23, 6312-6335, doi:10.1175/2010JCLI3679.1.

Wu, T., and Coauthors, 2010: The Beijing Climate Center atmospheric general circulation model: Description and its performance for the present-day climate. Climate Dyn., 34, 123-147, doi:10.1007/s00382-008-0487-2.

Xue, Y., and Coauthors, 2010: Intercomparison and analyses of the climatology of the West African monsoon in the West African Monsoon Modeling and Evaluation project (WAMME) first model intercomparison experiment. Climate Dyn., 35, 3-27, doi:10.1007/s00382-010-0778-2.

Yukimoto, S., and Coauthors, 2012: A new global climate model of the Meteorological Research Institute: MRI-CGCM3-model description and basic performance. J. Meteor. Soc. Japan, $\mathbf{9 0 A}$, 23-64, doi:10.2151/jmsj.2012-A02.

Zhang, C., D. S. Nolan, C. D. Thorncroft, and H. Nguyen, 2008: Shallow meridional circulations in the tropical atmosphere. J. Climate, 21, 3453-3470, doi:10.1175/2007JCLI1870.1.

Zheng, X., and E. A. B. Eltahir, 1998: The role of vegetation in the dynamics of West African monsoons. J. Climate, 11, 20782096, doi:10.1175/1520-0442-11.8.2078. 